
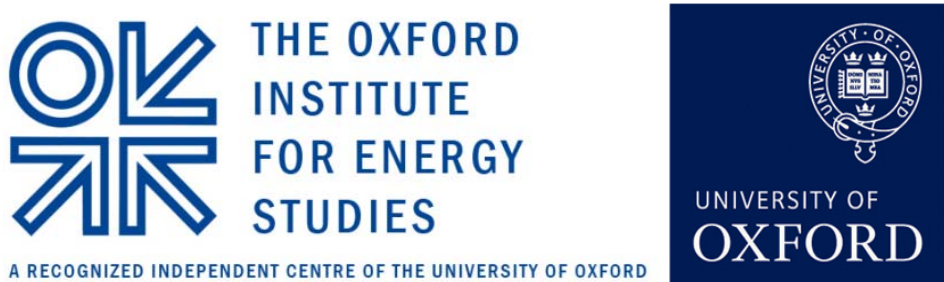

\title{
Natural Gas Price Volatility in the UK and North America
}

Sofya Alterman

NG 60

February 2012 
The contents of this paper are the author's sole responsibility. They do not necessarily represent the views of the Oxford Institute for Energy Studies or any of its members.

Copyright (C) 2012

\section{Oxford Institute for Energy Studies}

(Registered Charity, No. 286084)

This publication may be reproduced in part for educational or non-profit purposes without special permission from the copyright holder, provided acknowledgment of the source is made. No use of this publication may be made for resale or for any other commercial purpose whatsoever without prior permission in writing from the Oxford Institute for Energy Studies.

ISBN

$978-1-907555-43-5$ 


\section{Preface}

Sofya Alterman made contact with the Natural Gas Research Programme in 2010 while undertaking a project on LNG as part of her Harvard MBA. This working paper on natural gas price volatility is the result of her subsequent research at the OIES in 2011.

Lacking a commonly understood definition, price volatility is an often over-generalised term with different meanings to different constituencies. This should not detract from the importance of volatility, however. To traders volatility is a source of revenue, to energy intensive industrial end-users it is often perceived as a threat. Midstream utilities actively work to manage volatility in order to deliver a 'dampened' price offer to end-user customers.

In this working paper Sofya summarises the insights from an analysis of natural gas, crude oil and oil products price time series to answer the questions 'are natural gas prices inherently more volatile than those of oil ?' and the more interesting question 'can episodes of markedly different gas price volatility be explained by underlying market fundamentals ?'

Sofya's research involved a painstaking analysis of 14 years-worth of daily price data along with the investigation of the likely drivers of the volatility patterns uncovered. Her results both confirm the relevance of obvious drivers but also show how these can be blunted or offset by other compensating effects, some of which are less widely acknowledged.

As with so much of the research produced by the Natural Gas Research Program at the Oxford Institute for Energy Studies I hope this paper provokes thought and discussion amongst recipients and important insights into this key aspect of natural gas markets, especially at a time when trading hub development continues apace in Continental Europe.

Howard V Rogers

Director of Natural Gas Research 


\section{Contents}

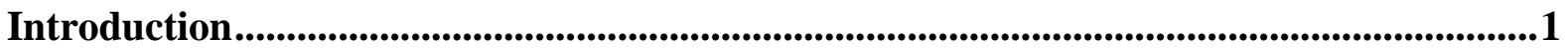

1 Terminology and methodology ....................................................................................................2

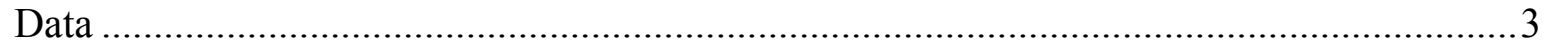

2 Are natural gas prices more volatile than oil prices? ...............................................4

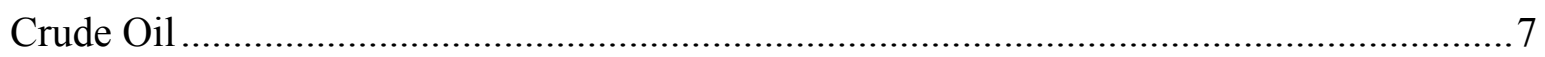

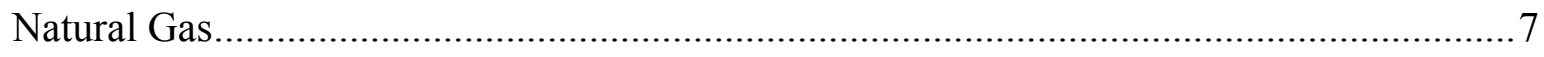

3 Patterns and episodes of crude oil price volatility: WTI and Brent.............................9

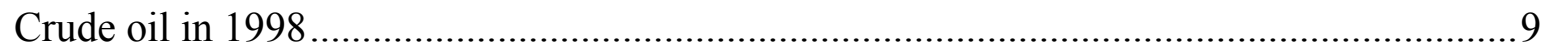

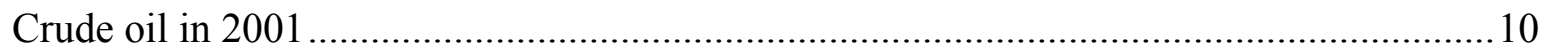

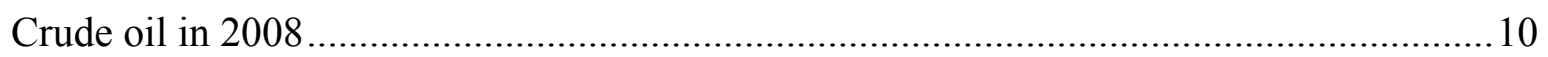

4 Patterns and episodes in natural gas price volatility - Henry Hub..............................12

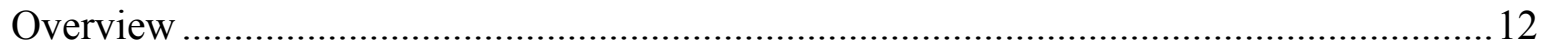

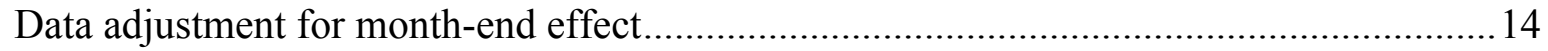

Factors affecting natural gas fundamentals and volatility in the US................................. 16

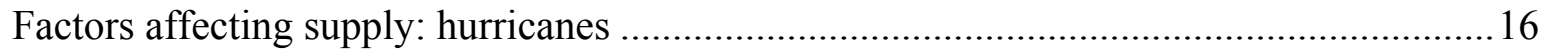

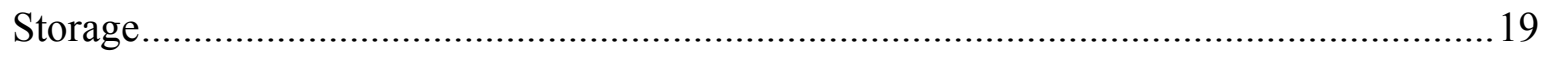

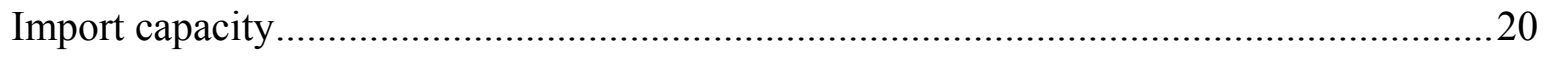

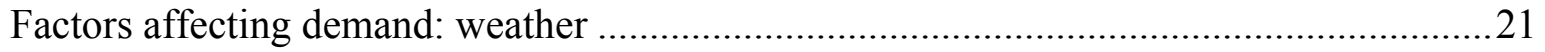

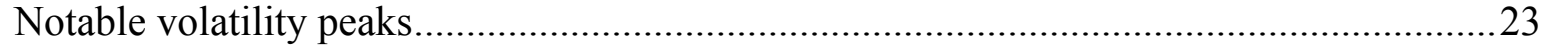

5 Patterns and episodes in natural gas price volatility - NBP ....................................26

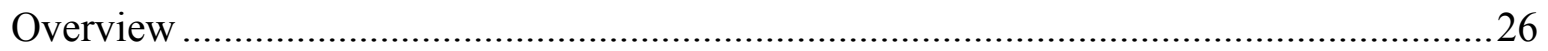

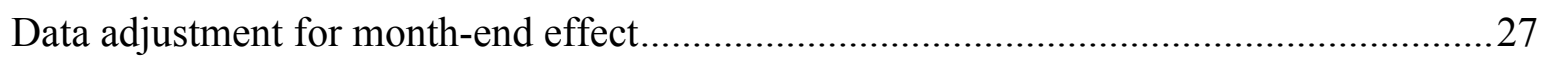

Understanding patterns and periods of increased NBP price volatility ............................28

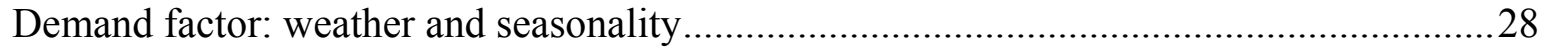

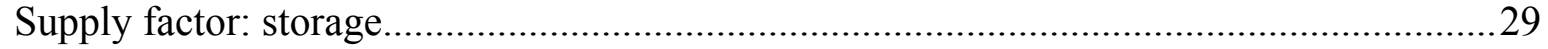

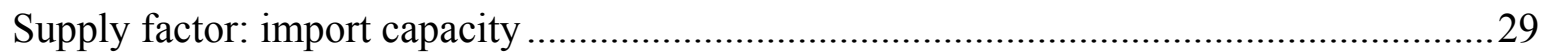

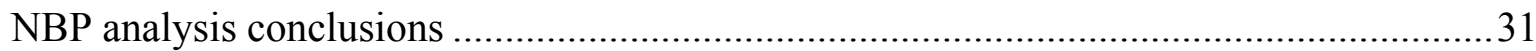

6 Gasoil and heating oil volatility: factors and linkages to natural gas ..........................34

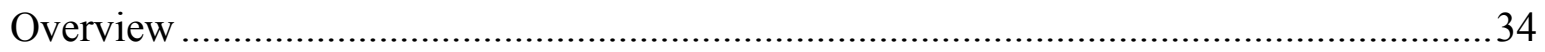

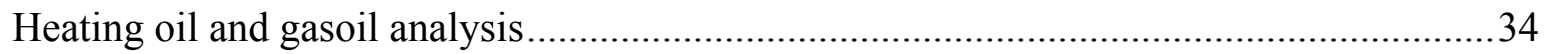

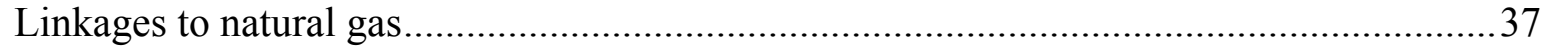

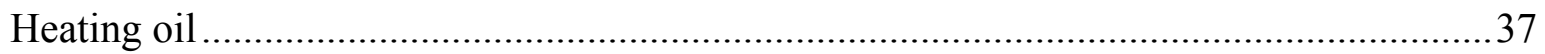


7 Conclusions.

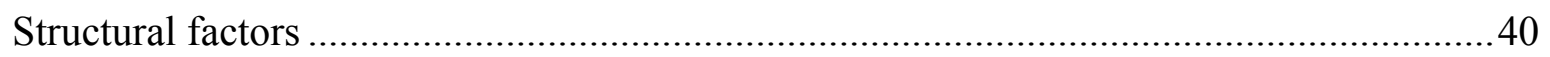

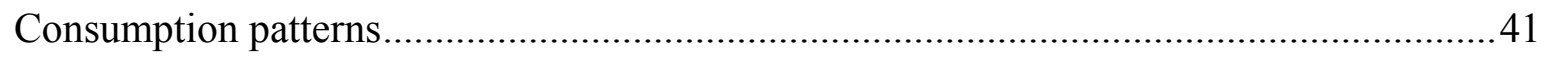

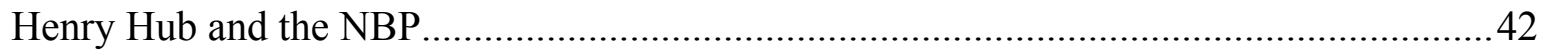

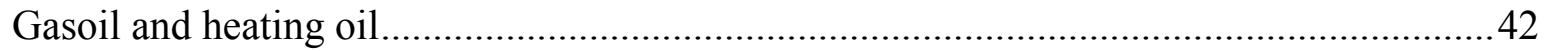

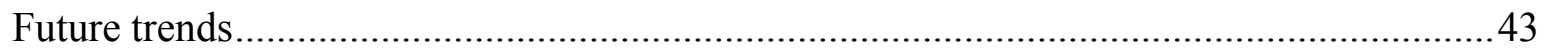

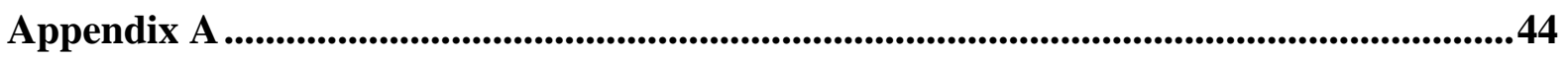

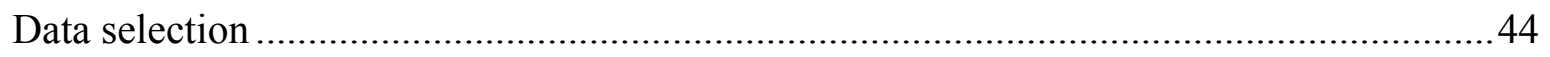

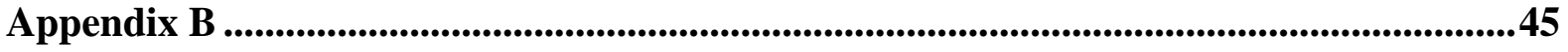

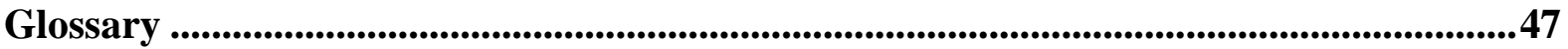

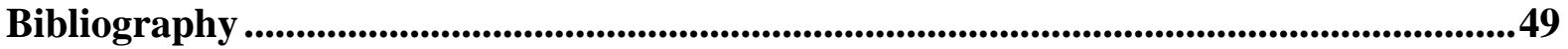

\section{Figures}

Figure 1: Spot prices for Henry Hub (HH), Natural Balancing Point (NBP) and BAFA 1997 -

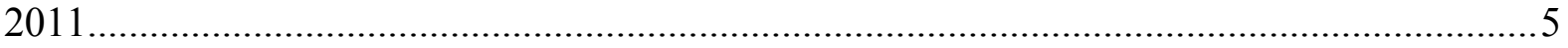

Figure 2: Monthly price volatility of natural gas and crude oil (HH, NBP, WTI, Brent) .........6

Figure 3: Annual volatility band for Henry Hub, WTI, Brent and NBP (from left to right

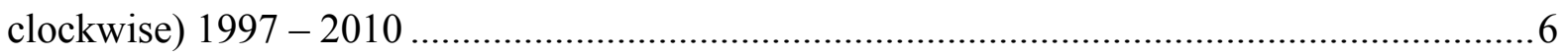

Figure 4: Monthly price volatility of WTI and Brent …......................................................

Figure 5: OPEC output decisions between 1997 and 2001_................................................ 10

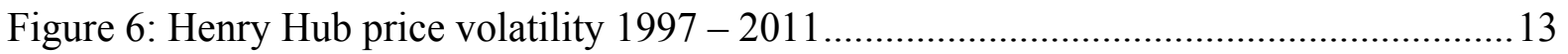

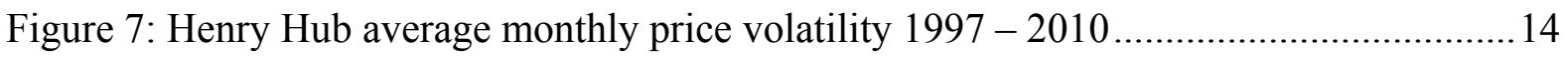

Figure 8: Henry Hub front-month original and controlled volatility ................................... 15

Figure 9: Henry Hub average monthly price volatility 1997 - 2010: original and controlled 16

Figure 10: US Offshore production (Gulf of Mexico) and major hurricanes ........................ 17

Figure 11: Monthly \% change in Gulf of Mexico marketed production ............................... 18

Figure 12: US working natural gas in storage actual compared with five-year average .........19

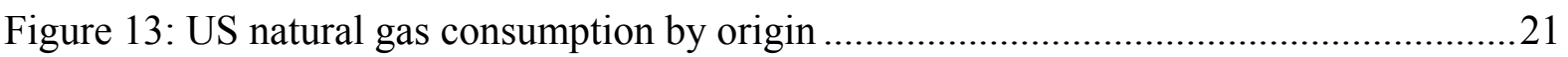

Figure 14: US winter weather and average winter volatility $1997-2010$ (red bars $=$ warmer

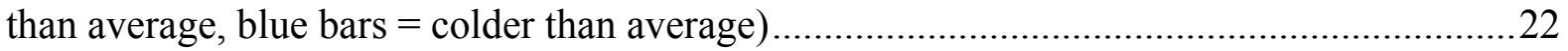

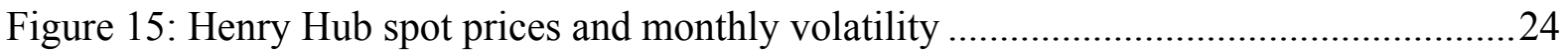

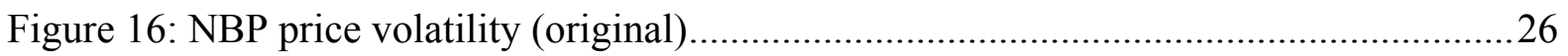




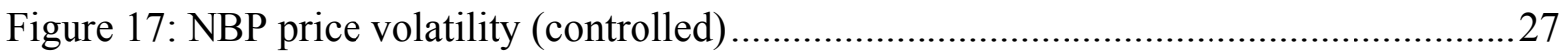

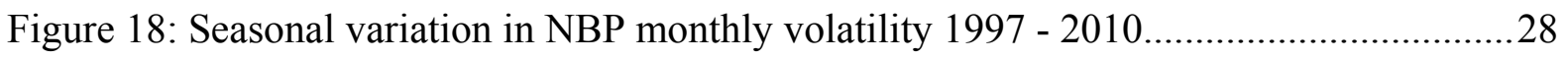

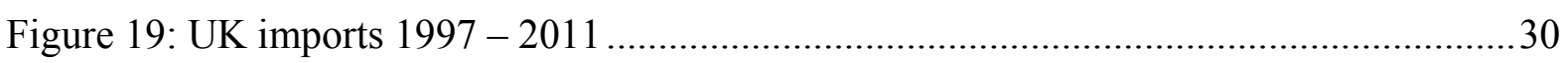

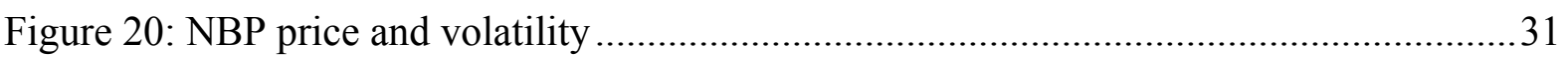

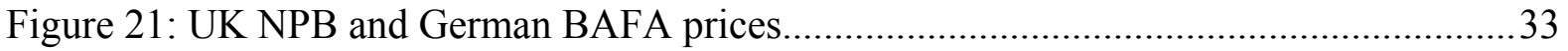

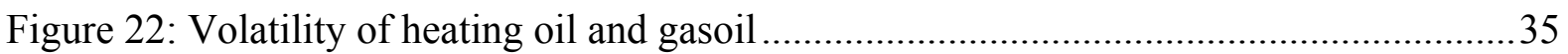

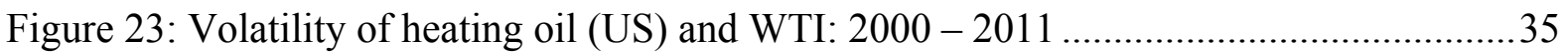

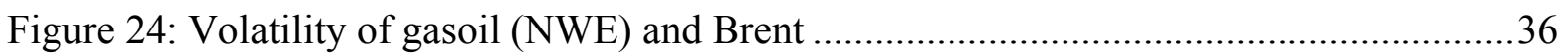

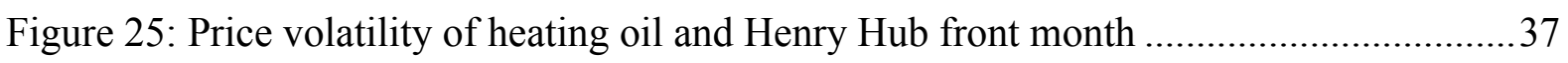

Figure 26: Price volatility of gas oil and NBP front month (controlled) .................................38

\section{Tables}

Table 1: Correlations table for WTI, Brent, NBP and HH: February 1997 - May 2011 _........8

Table 2: Volatility correlations: heating oil against Henry Hub and WTI .............................37

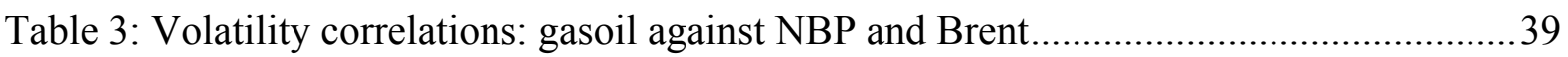




\section{Introduction}

It is often asserted that the price of natural gas in traded markets is significantly more volatile than that of oil, though specific evidence is rarely offered. Yet price volatility has direct consequences for a variety of natural gas market constituents such as traders, investors and, ultimately, the end users. The goal of this study is to quantify the volatility of both natural gas and crude oil, and in comparing the two understand whether natural gas volatility indeed exceeds that of crude oil and, if this is the case, seek an explanation.

Moreover, the assumed higher volatility of natural gas as compared to oil is often given as a reason why long-term supply contract prices for natural gas should continue to be linked to oil or oil products rather than to a traded gas hub index. With the expansion of the trading hubs in Europe and the greater availability of un-contracted spot gas, this premise is being questioned by many market participants. This paper aims to quantify the relative volatilities of oil and gas and identify the drivers as well as the exogenous factors that impact both commodities. Expectations for volatility going forward are described in the summary and conclusion of this paper.

A literature survey revealed several studies focused on the historical volatility of natural gas and its drivers over periods of time in the last twenty years. ${ }^{1}$ Using these sources as a starting point and a basis for comparison, this paper employs quantitative techniques to examine the volatility of natural gas and crude oil prices in the US and UK markets over the period from 1997 to 2011.

This period saw significant developments in gas markets on both sides of the Atlantic, including the rapid development of shale gas in the US, the continued decline in UK domestic gas production, the development of Continental European trading hubs, and a significant increase in global LNG supply and European LNG imports. Given the general increase in available data on supply and demand side fundamentals since 2000 , it is possible to explore whether periods of higher or lower volatility can be linked to exceptional market fundamentals events.

After a review of terminology and methodology in Chapter 1, the question of whether gas prices are indeed more volatile than those of oil is addressed in Chapter 2. Chapter 3 focuses on periods of high oil price volatility and the possible reasons why such episodes occurred. Chapter 4 looks in detail at US (Henry Hub) gas price volatility and seeks to explain the underlying reasons for high and low volatility episodes in this market. Chapter 5 employs the same approach for the UK (NBP) natural gas market prices.

In Chapter 6 the possible link between natural gas price volatility and that of oil products is examined. Chapter 7 draws together the paper's findings and conclusions and builds a picture of what future events might give rise to changed levels of gas price volatility, relative to the fairly low levels observed in 2011.

\footnotetext{
${ }^{1}$ Pindyck 2004, Mu 2004, EIA 2007, Henning, Sloan and De Leon, American Gas Foundation 2003
} 


\section{Terminology and methodology}

It is important to note here that some of the statements about natural gas and oil volatility may stem from the inconsistent comparison of the prices for the two commodities; that is, as a result of comparing the 'spot' prices for natural gas and crude oil. Due to the differing physical nature of the two commodities, the spot price refers to a different delivery timeframe for oil and gas. In this study, we will focus on the front-month contracts for both commodities to eliminate such a time frame inconsistency.

Several accepted approaches to measuring price volatility exist. They can be divided into two categories - those measuring volatility in absolute terms, and those based on the change in price relative to the initial price. The latter is generally referred to as the 'returns' method and measures percentage change in daily prices. This is the frame of reference normally used by traders, risk managers and other market participants concerned with short-term price changes.

As the goal of this paper is to analyze volatility across several commodities (the prices of which are expressed in different units), the 'returns' method is more appropriate. This approach is also consistent with that used in previous papers measuring natural gas volatility. ${ }^{2}$

The returns method is calculated as the standard deviation of daily relative changes in price. The daily relative price change is computed using a natural $\log$ transformation. Volatility itself is then calculated by multiplying the standard deviation of the daily logarithmic price changes, $\mathrm{p} \Delta$, for all trading days within a certain time period by the square root of the number of trading days within the time period. For the monthly volatility calculation, the 21 trading days convention is used.

Overall, volatility as measured by the 'returns' method is affected to the greatest degree by sharp price changes (up or down) from day to day. This means that even if prices rise or fall significantly, albeit gradually, during a given month, the volatility calculation will not produce a high value. For a more detailed description of alternative volatility measurement methods, see Appendix A.

To compare the relative volatility of natural gas and crude oil, the Pearson correlation was used. This is the mostly widely used correlation calculation method, which is also used in the Microsoft Excel correlation function. This measure provides a quantitative assessment of the degree to which two independent variables move together. For the purposes of this paper, it was important to understand whether volatility spikes in natural gas were also accompanied by volatility increases in crude oil and vice versa. ${ }^{3}$

\footnotetext{
${ }^{2}$ See EIA 2007, Henning and, Sloan and de Leon, American Gas Foundation 2003

${ }^{3}$ StatSoft Electronic Statistics Textbook, http://www.statsoft.com/textbook/basic-statistics/\#Correlations
} 


\section{Data}

Natural gas contracts are traded on the traditional over-the-counter commodities markets (OTC) as well as on exchanges such as NYMEX (the New York Mercantile Exchange) for Henry Hub contracts and ICE (Intercontinental Exchange) Futures Europe for NBP contracts. The data for the volatility analysis presented below was obtained from the respective exchanges and is available in the public domain. ${ }^{4}$ As both of the relevant exchanges are government regulated, they provide, in the author's view, an accurate and reliable source of data.

Given that one of the key objectives of this paper is to compare the price volatility of natural gas with that of crude oil, the front month futures contract was chosen as the main data unit for both commodities. As mentioned above, while natural gas is traded in the 'spot' or 'cash' market as well as day-ahead, the shortest duration contract for crude oil is the month-ahead or the 'front month'. Choosing the front-month futures contracts for both oil and gas aligned the delivery time period for both commodities, thus permitting a more relevant comparison.

\footnotetext{
${ }^{4}$ See Appendix A for comparison of exchange data and OTC data and an overview of differences.
} 


\section{Are natural gas prices more volatile than oil prices?}

To answer this question, the monthly volatility of natural gas and crude oil was calculated using the 'returns' methodology described above, and the results compared. While crude oil is considered a global commodity, it is traded in several markets in which defined 'blends' or 'marker crudes' differ in physical characteristics such as sulfur content and API gravity ${ }^{5}$. In this analysis both the US WTI (West Texas Intermediate) and UK Brent front-month futures data series were used to test for any differences between these markets.

For natural gas, Henry Hub front-month futures and NBP front-month futures were used. Unlike oil, natural gas trades in different markets using different price measurement units. The pricing and volatility dynamics in each of these markets were evaluated and compared.

The global natural gas market can be segmented into four regional markets:

1. United States: liberalized and extremely liquid; the 'market of last resort'; geographically isolated.

2. UK: liberalized, fairly liquid, subject to arbitrage between the spot gas traded on NBP and Continental European long-term contract gas which is priced with reference to oil products.

3. Continental Europe: largely contract gas, indexed to oil products, with spot gas purchases possible once take-or-pay levels are exceeded on the oil-indexed long-term contracts.

4. FSU, Asia and South America: no 'onshore' trading hubs, gas prices largely based on stateregulated levels or long-term oil linked contracts for regional pipeline gas and LNG, with some spot LNG cargo purchases in recent years.

Substantial price differences have historically existed between these four geographic areas due to the differences in price formation between the gas sold on long-term contracts, historically linked to crude oil or oil products, and the spot markets in the US and UK, driven largely by supply and demand fundamentals.

With respect to pricing across these regional markets, Figure 1 presents historical prices for Henry Hub, NBP and the German Border Price (BAFA), which can be used as a proxy for longterm oil-indexed contracts that dominate the continent.

\footnotetext{
${ }^{5} \mathrm{API}$ gravity (American Petroleum Institute gravity) is a measure of how heavy or light a petroleum liquid is compared to the same volume of water. If its API gravity is greater than 10 , it is lighter and floats on water; if less than 10, it is heavier and sinks. API gravity is thus an inverse measure of the relative density of a petroleum liquid and the density of water, but it is used to compare the relative densities of petroleum liquids
} 
Figure 1: Spot prices for Henry Hub (HH), Natural Balancing Point (NBP) and BAFA 1997 $-2011^{6}$

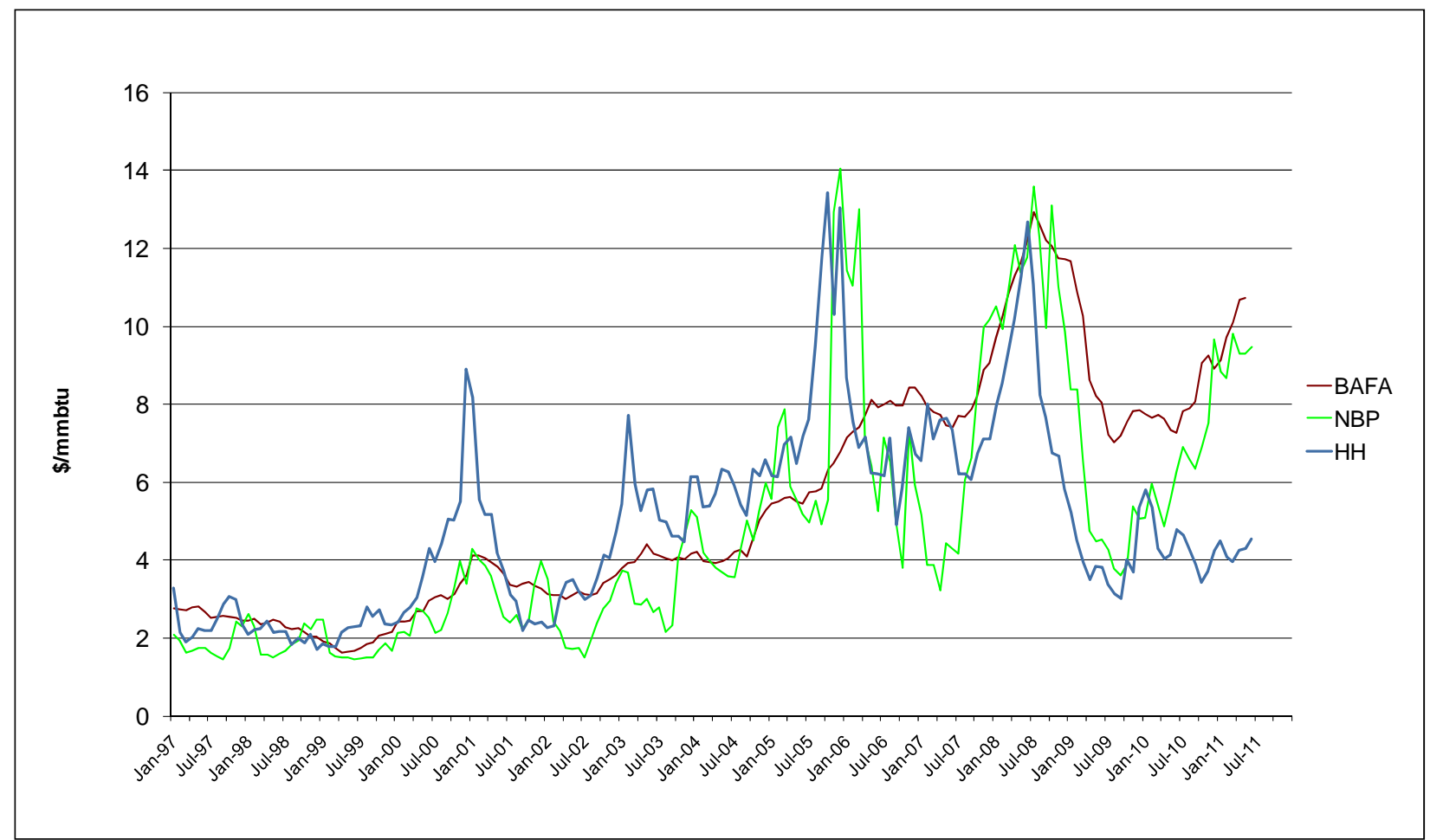

Source: EIA, Argus, BAFA

Historically there has been limited gas trade-flow linkage between the US and UK natural gas markets. With the exception of pipeline imports from Canada, and to a lesser degree from Mexico and a small and declining level of LNG imports, the US gas market has been largely self-sufficient and, therefore, it was hypothesized, influenced by a different set of factors from those affecting the UK gas market.

Figure 2 illustrates the volatility calculation results for the four crude oil and natural gas data series. The first observation from the graph is that natural gas prices (as illustrated by the NBP and Henry Hub plots in blue and green, respectively) indeed exhibit a substantially higher level of volatility than the oil prices (as illustrated by WTI and Brent plots in red and orange, respectively). Typically, natural gas front-month futures show an average volatility $50 \%$ higher than the crude oil front-month futures. These results are consistent with previous analysis of price volatility in the natural gas market. ${ }^{7}$

\footnotetext{
${ }^{6}$ BAFA: The German Federal Office of Economics and Export Control website which reports natural gas prices, production, imports, exports and storage inventory changes: http://www.bafa.de/bafa/en/index.html

7 Henning, Sloan and De Leon, American Gas Foundation 2003
} 
Figure 2: Monthly price volatility of natural gas and crude oil (HH, NBP, WTI, Brent)

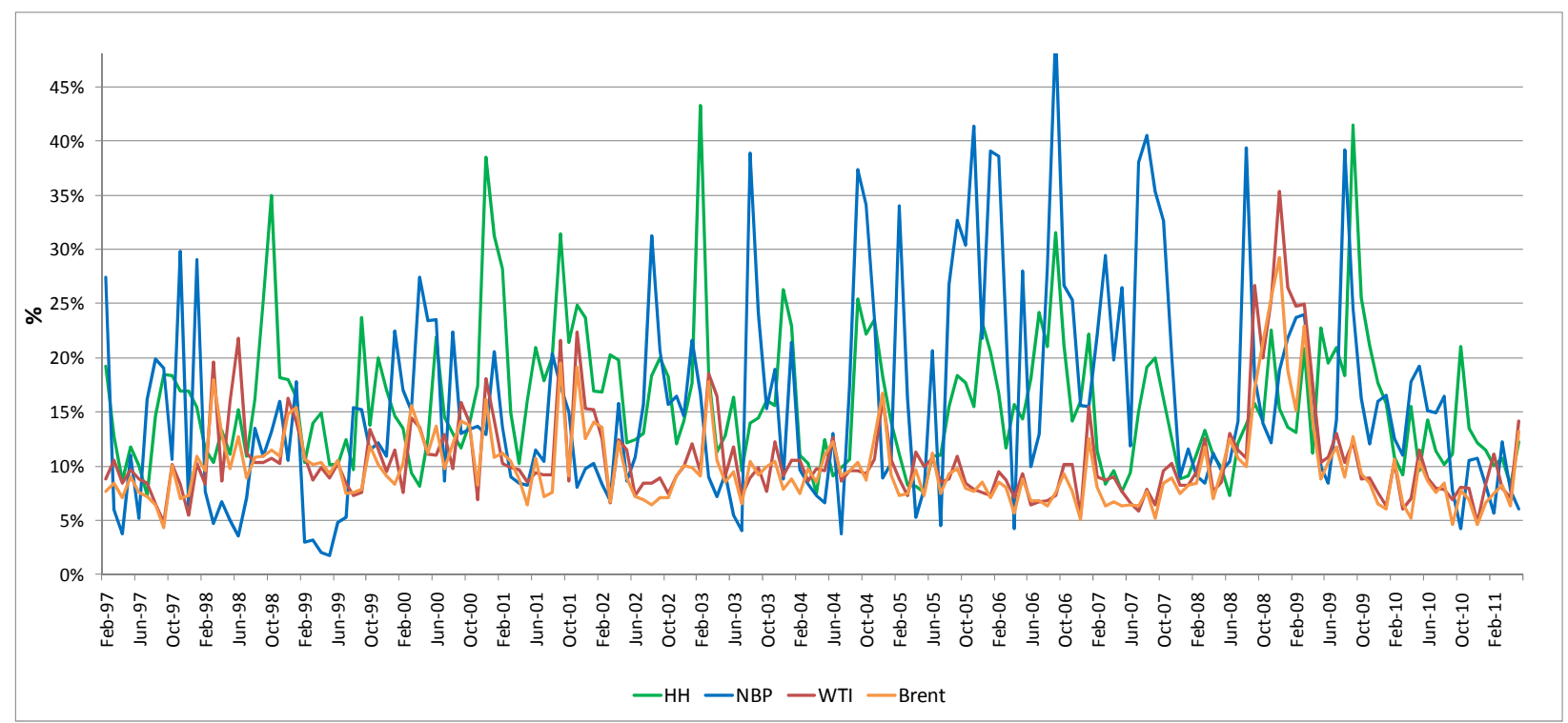

Source: Author's own analysis

The four graphs in Figure 3 underline this finding, presenting an even more extreme view of the natural gas and oil volatilities. Figure 3 shows the annual volatility band for each commodity series, calculated by taking the difference between the maximum and minimum monthly volatilities for each commodity in any given year.

Figure 3: Annual volatility band for Henry Hub, WTI, Brent and NBP (from left to right clockwise) 1997 - 2010
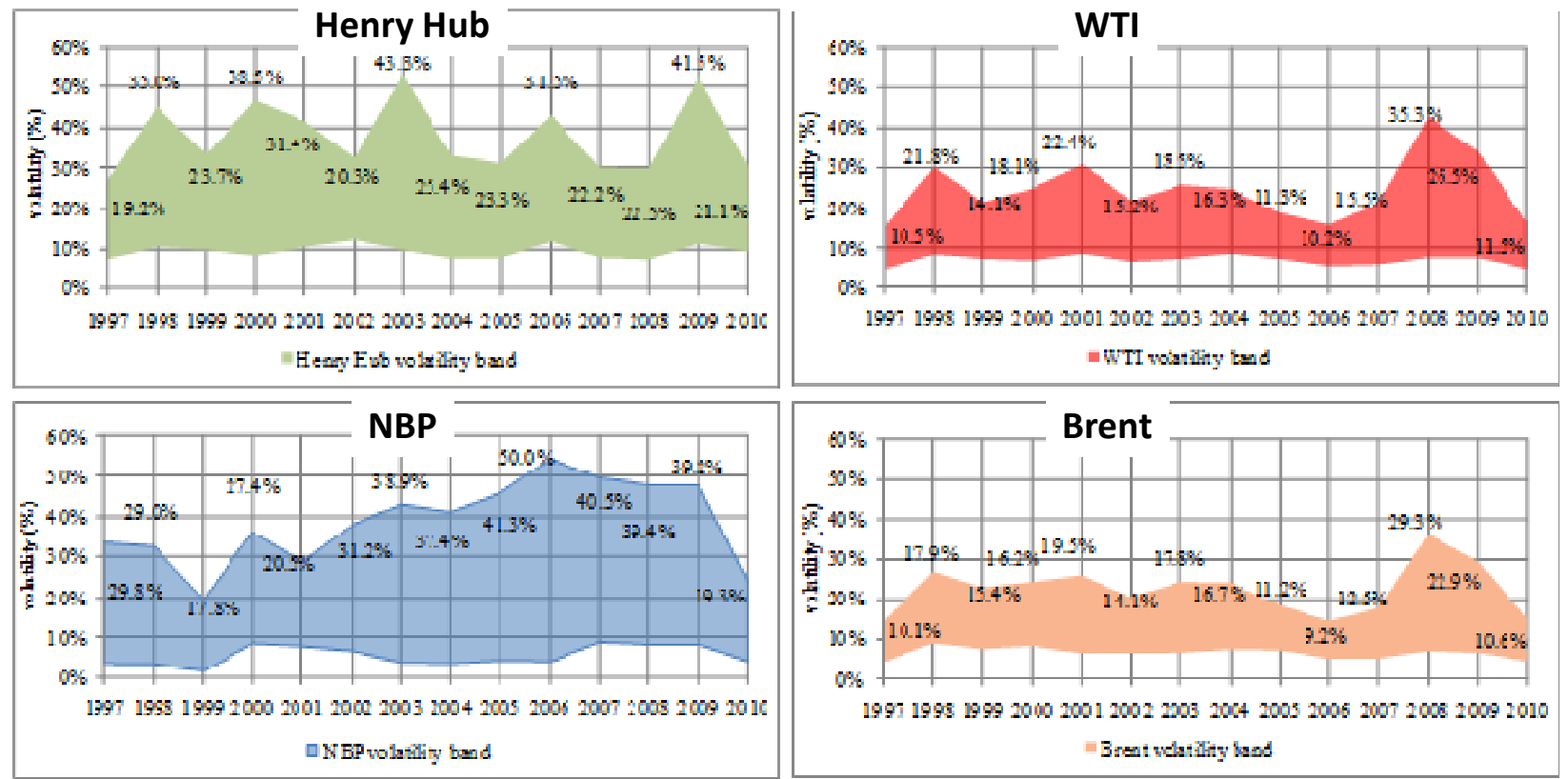

Source: Author's own analysis 
The following observations made from examining the natural gas and crude oil volatility results separately are:

\section{Crude Oil}

Crude oil has a lower overall volatility than natural gas, with three distinct episodes of increased volatility in 1998, 2001 and 2008. These occurrences are explained below.

1. WTI exhibits a slightly higher average volatility: $10.8 \%$ compared with $9.9 \%$ for Brent. This could be due to the physical storage and pipeline capacity constraints around Cushing, Oklahoma, which is a major supply hub connecting the Gulf Coast suppliers with northern consumers. As the most significant trading hub for North American crude, Cushing is also the price settlement point for WTI contracts on NYMEX. ${ }^{8}$

WTI also has a higher standard deviation of monthly volatility at $4.5 \%$, as against $3.8 \%$ for Brent. This indicates that WTI generally has slightly higher peaks and lower troughs than Brent.

2. Examining the minimum and maximum volatility points between 1997 and 2010 (as in Figure 3 ) shows that the minimum volatility of Brent is around $6.9 \%$, while the minimum volatility of WTI is around $6.5 \%$. In terms of maxima, for Brent maximum volatility is some $16 \%$, while WTI has a higher general maximum of $17.7 \%$. This is consistent with point 3 above.

3. Finally, the WTI and Brent volatility data exhibits a strong positive correlation of +0.90 compared with only +0.25 for NBP and Henry Hub volatility data.

\section{Natural Gas}

1. Interestingly, the two natural gas data series showed an almost equivalent average monthly volatility. This is surprising, given the difference in the fundamentals influencing the two markets and the relative physical isolation of the US natural gas market from the rest of the world.

2. While the average volatility of the two natural gas series is almost equivalent, their volatility bands differ considerably. The minimum volatility for Henry Hub fluctuates closely around the $9 \%$ mark and maximum volatility reaches $43 \%$ at its highest. For the NBP, minimum volatility is on average around $5.7 \%$, while the maximum extends higher, to $50.0 \%$.

3. Both natural gas graphs have significantly higher peaks than those for crude oil. However, Henry Hub exhibits distinctly higher volatility peaks than the NBP between February 97 and

\footnotetext{
${ }^{8}$ For more information on Cushing, Oklahoma, capacity issues see: Vertical Integration and the Cushing Crunch, Commodities Now, August 2003; and Major Oil Storage Owners at Cushing, Oklahoma, Reuters, February 2011. http://www.commodities-now.com/commodities-now-news/power-and-energy/7253-verticalintegration-and-the-cushing-crunch.html
} 
May 2004, while the NBP peaks exceed those of Henry Hub post August 2005, (with the exception of October 2009).

4. Finally, there is no significant correlation between the natural gas and oil volatilities. Comparing the geographically corresponding series, we find the correlation between WTI and Henry Hub is +0.13 , while the correlation between Brent and NBP is -0.07 .

Table 1: Correlations table for WTI, Brent, NBP and HH: February 1997 - May 2011

\begin{tabular}{|l|c|c|c|c|}
\hline & WTI & Brent & NBP & HH \\
\hline WTI & 1.00 & 0.90 & $n / a$ & 0.13 \\
\hline Brent & 0.90 & 1.00 & -0.07 & n/a \\
\hline NBP & n/a & -0.07 & 1.00 & 0.25 \\
\hline HH & 0.13 & n/a & 0.25 & 1.00 \\
\hline
\end{tabular}

Source: Author's own analysis

The following chapters provide additional evidence for the phenomena described above and explain, where possible, the likely factors influencing and driving volatility for these four data series. 


\section{Patterns and episodes of crude oil price volatility: WTI and Brent}

Crude oil front-month futures experienced three distinct periods of increased volatility between 1997 and 2011. Figure 4 illustrates these occurrences graphically.

Figure 4: Monthly price volatility of WTI and Brent

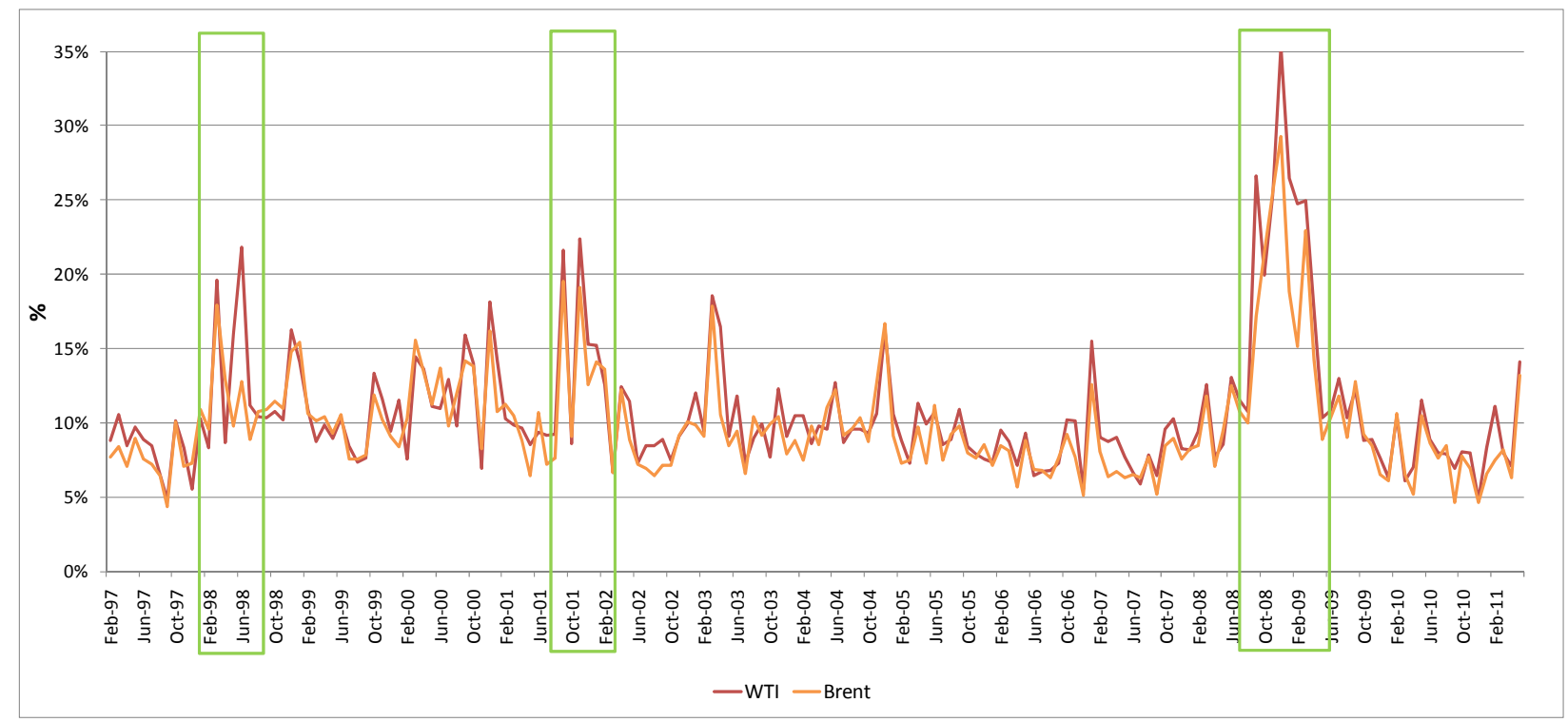

Source: Author's own analysis

\section{Crude oil in 1998}

In 1998 both WTI and Brent experienced a significant volatility peak amidst falling oil prices. In March 1998 the volatility for both data series reached almost 20\% following the unfolding of the Asian Financial Crisis, which precipitated a fall in global demand and sent oil prices plummeting. WTI experienced another volatility peak of over $20 \%$ in June 1998, though the reason for this is not readily apparent. One possible explanation is the link to the second oil output cut by OPEC that was announced after the June 1998 gathering of the OPEC members, just three months after the initial output cut in April 1, 1998, (see Figure 5). The difference in the volatility response of Brent and WTI to the OPEC output cut could stem from the difference in expectations in the pre-announcement period. ${ }^{9}$

\footnotetext{
${ }^{9}$ Schmidbauer, Rosch, p 15
} 
Figure 5: OPEC output decisions between 1997 and 2001

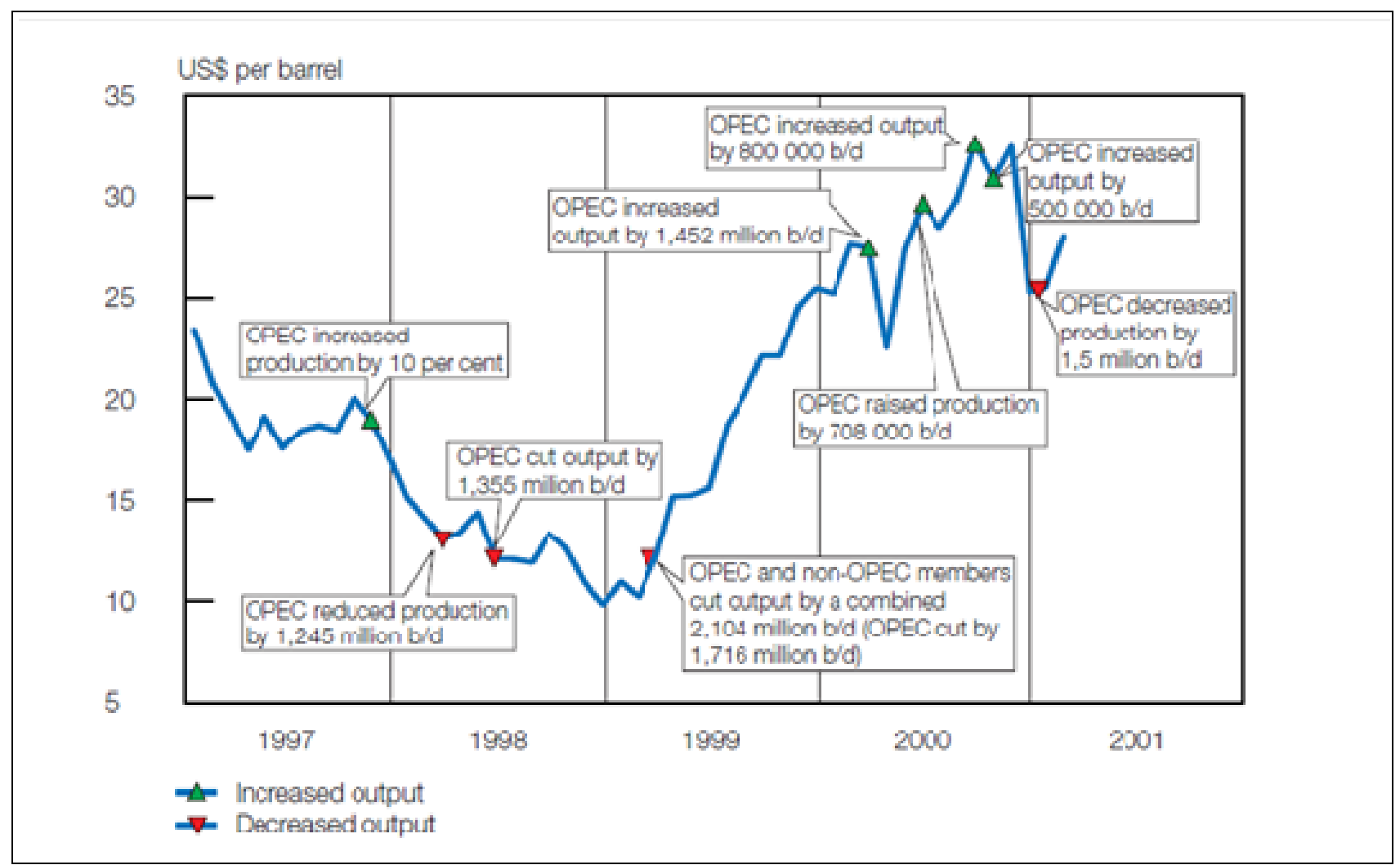

Source: Farrell, Kahn, Visser

\section{Crude oil in 2001}

The second episode of increased volatility during the observed period took place in September and November 2001, when both WTI and Brent data sets exhibited an almost equal volatility of over $20 \%$ in each of the months. However, these increased volatility occurrences appear to have been precipitated by two very different world events. In September 2001 the terrorist attack on the Twin Towers in New York created the expectation of a US recession. The WTI price fell from $\$ 27.6$ per barrel on September 10 to $\$ 22.5$ per barrel by October 10 . Then in November 2001 the collapse of Enron, the largest bankruptcy in US history up to that point, further exacerbated the situation and the futures price fell to $\$ 17.5$ per barrel by November 15 , recovering briefly and ending the year at $\$ 19.8$ per barrel. While the two events differ in nature, both can be categorized as exogenous to the supply/demand framework of the global oil market.

\section{Crude oil in 2008}

The third volatility episode far exceeded in magnitude the earlier two. In December 2008 Brent volatility reached $30 \%$ and WTI volatility reached $35 \%$ on fears of the global slowdown resulting from the Global Financial Crisis. To add context, in July 2008 oil prices reached an alltime high, with the futures peaking at $\$ 145.3$ per barrel on July 3, rising on the back of the 2007 
global economic boom. From mid-July 2008 oil futures prices began to fall gradually but persistently, reaching \$66 per barrel by the end of October, and \$34 per barrel by December 19 .

It is important to note that throughout this period the Brent front-month futures volatility increased gradually from $10 \%$ to the December peak of $30 \%$, thereafter dropping to $20 \%$ and $15 \%$ in January and February respectively. At the same time, the WTI front-month volatility jumped from $10 \%$ to $25 \%$ in September, falling again in October and then continuing to rise through December. Throughout this period the WTI volatility stayed somewhat above that of Brent, apart from during October when it was slightly lower. As stated above, the reason behind the higher volatility of WTI could be that its main trading point is landlocked, with crude oil flows subject to pipeline capacity constraints around Cushing, Oklahoma ${ }^{10}$.

\footnotetext{
${ }^{10}$ For more information on Cushing, Oklahoma, capacity issues see: Vertical Integration and the Cushing Crunch, Commodities Now, August 2003; and Major Oil Storage Owners at Cushing, Oklahoma, Reuters, February 2011. http://www.commodities-now.com/commodities-now-news/power-and-energy/7253-verticalintegration-and-the-cushing-crunch.html
} 


\section{Patterns and episodes in natural gas price volatility - Henry Hub}

\section{Overview}

Henry Hub is a physical trading hub located at the junction of several large gas pipelines in Louisiana and is the main trading hub in the North American natural gas market. It is the pricing point for the natural gas futures traded on the New York Mercantile Exchange (NYMEX), as it serves as the official delivery location for these contracts. While other regional hubs are currently in operation, they generally price natural gas based on a location differential (a spread) to each respective market from the Henry Hub location. ${ }^{11}$

Before proceeding with the analysis of the volatility in Henry Hub contracts, it is important to focus briefly on the relative volatility of Henry Hub and NBP. Earlier in this paper it was noted that the average volatility of the front-month futures contracts trading on these two hubs was broadly equal during the period between 1997 and 2011. There is no obvious explanation for this phenomenon, given the geographic separation of the two markets and the differences in supply/demand dynamics in each.

A possible factor could be fuel-switching in the US power sector between natural gas and distillate (No. 2 fuel oil, which is a product of oil refining) when the prices of the two fuels converge. Rogers ${ }^{12}$ showed that between 2000 and 2009 the price of natural gas rose in several instances up through fuel oil price levels and at times to the level of distillate prices. That paper also demonstrated and quantified the level of periodic switching between natural gas and oil products in the US power sector. Switching would create a link between natural gas prices and oil product prices. As Rogers demonstrates, the switching amounted to a relatively small volume, around $70 \mathrm{mmcm} /$ day. ${ }^{13}$. A link of a different nature exists in NW Europe, where oil-indexed priced natural gas under long-term contracts coexists with spot-priced gas flow from the UK. The interaction between gas supplies with different price formation mechanisms leads to arbitrage, which periodically can lead to a convergence between traded gas prices and those of oil products.

Superficially we might hypothesize that Henry Hub and NBP traded contracts have similar volatility levels due to linkages to oil products in both. However, European oil-indexed contract gas is linked not to current oil products prices but rather to a six- to nine-month rolling average of historic prices. This would severely dampen any linkage in volatility between oil products prices and long-term contract gas prices. Consequently, this phenomenon remains unexplained, other than that it might reflect periods of general energy sector price uncertainty and volatility.

Figure 6 presents the volatility of front month natural gas contracts traded on Henry Hub.

\footnotetext{
${ }^{11}$ An Overview of Natural Gas; Natural Gas.org, http://www.naturalgas.org/naturalgas/marketing.asp

${ }^{12}$ See Rogers 2010, P 12

${ }^{13}$ For further information on switching in the US see Jensen 2004 and Foss 2007, for switching in Europe see Stern 2007.
} 
Figure 6: Henry Hub price volatility 1997 - 2011

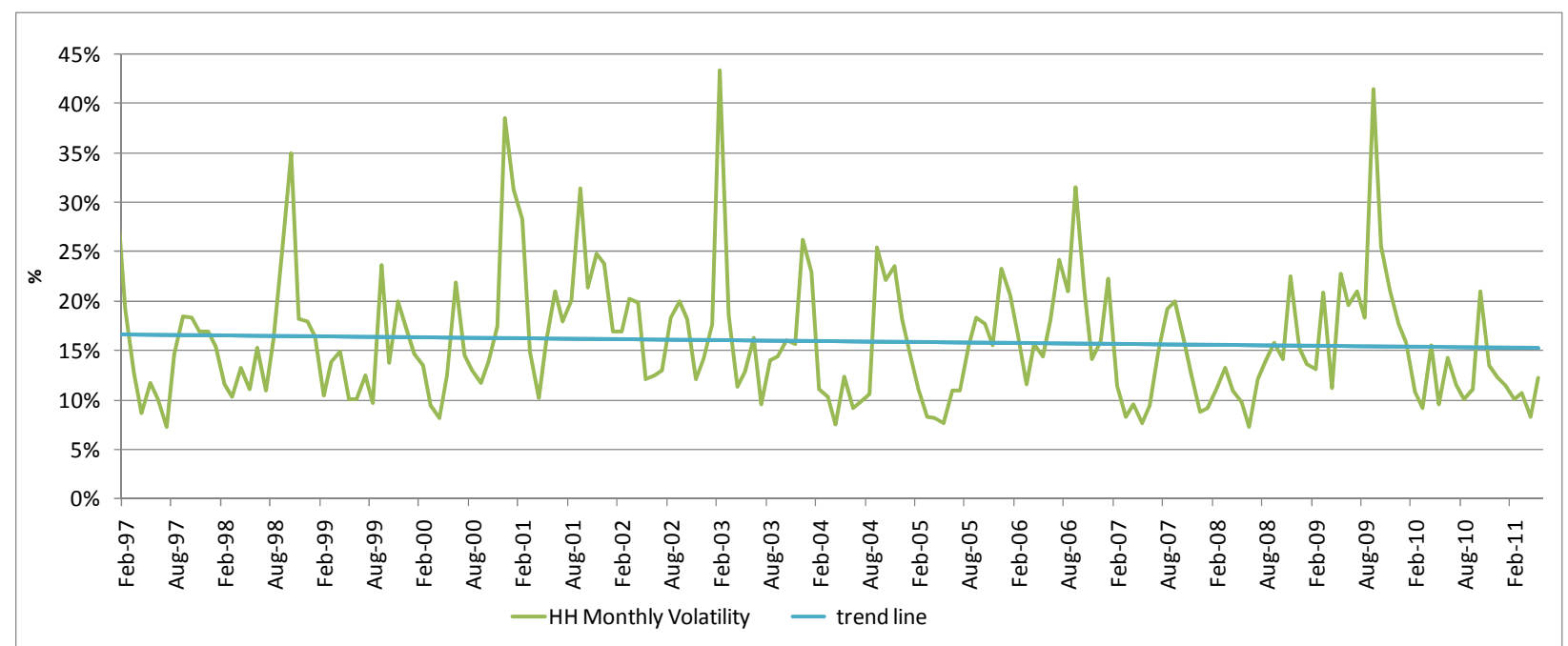

Source: Author's own analysis

The following key phenomena can be observed from Figure 6:

1. Unlike predictions stated in prior research ${ }^{14}$ volatility appeared to have decreased from 1997 to 2011 . The trend-line on the chart shows a decrease from approximately $17 \%$ to $15 \%$ over the stated period.

2. There was a slight decrease in average volatility in the second half of the period, starting at the end of 2005 .

3. Volatility dropped dramatically in 2010 and remained, with one exception, under $15 \%$ through June 2011.

Quantitative analysis of the data set yields an additional observation with respect to the seasonality of the volatility of Henry Hub natural gas contracts. From these calculations, the volatility tends to increase towards the end of the year and peaks in September and October. In 11 out of 14 years examined, these months produced the highest volatility levels for the year. This is likely to be because as the annual storage injection season ends and natural gas storage inventory reaches its peak, the gas available to meet the imminent winter demand becomes viewed as finite. At the same time, demand for the coming winter months is uncertain as weather conditions can change suddenly and unpredictably.

While the natural gas market participants incorporate weather predictions and supply levels into their expectations, the inherent uncertainty remains. Thus, fixed supply and uncertain demand create substantial volatility in the months leading up to the end of the storage filling season, that is, September and October, and during the early winter months when cold spells are likely to be

\footnotetext{
14 See Henning, Sloan and De Leon, American Gas Foundation 2003, pp. 3-32, where it is argued that given the demand trends in place at the time the price volatility would tend to increase overtime.
} 
still ahead. During the rest of the year average volatility is substantially lower as lower gas demand during the spring and summer months alleviates pressure on supply.

In some years the corollary to the above appears to have applied, where towards the end of the storage injection season there were concerns that working gas inventory would reach the maximum physical storage capacity before the onset of colder weather. In these circumstances, the prospect of a surplus of supply would lead to fears of depressed prices.

Figure 7: Henry Hub average monthly price volatility 1997 - 2010

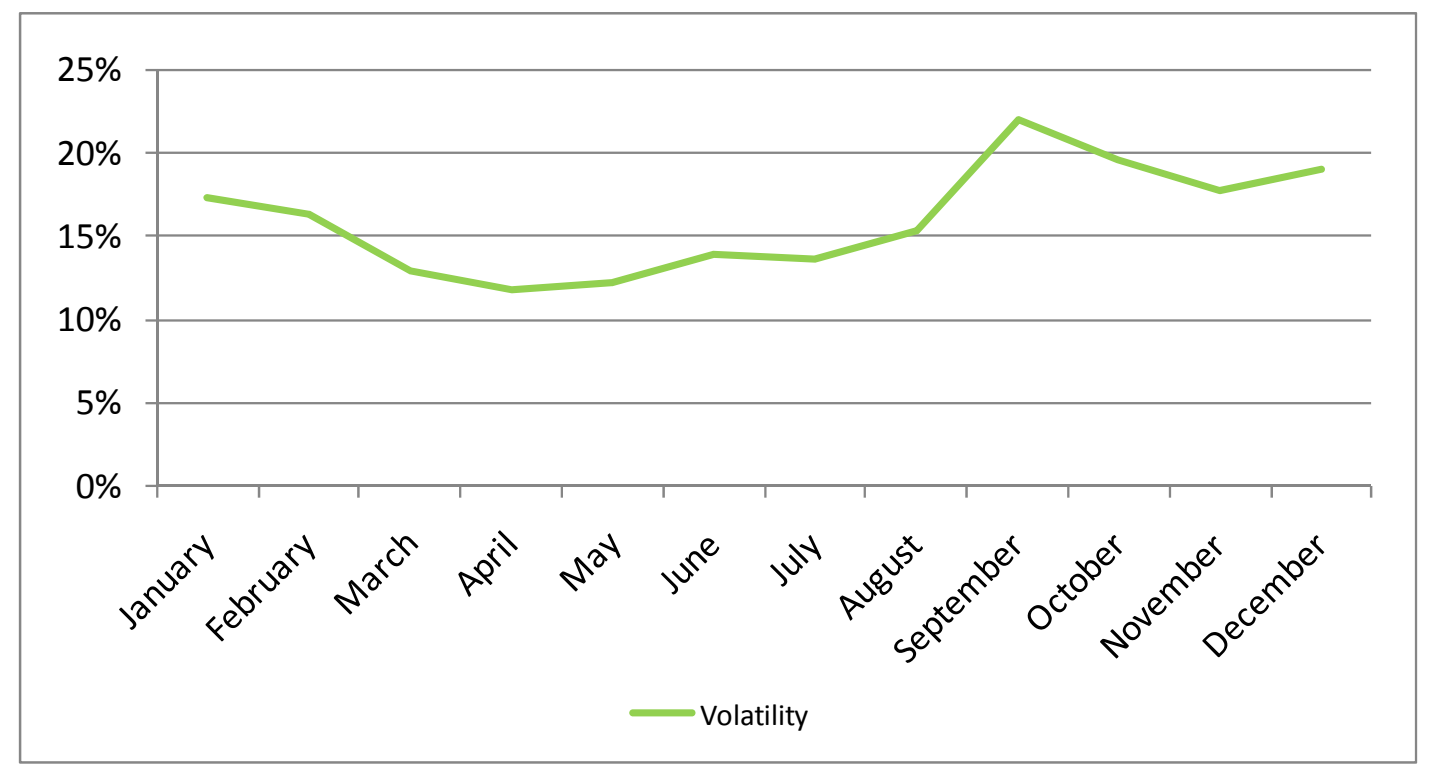

Source: Author's own analysis

Figure 7 demonstrates visually the seasonality of natural gas price volatility. The data used here is the average of Henry Hub volatility by month across the period from 1997 to 2010 . While the general pattern is useful to see, each individual year shows an idiosyncratic pattern of peaks and troughs that will be described later in this section of the paper.

Before going into the analysis of factors affecting natural gas price volatility in the US as well as individual instances of increased price volatility, it is important to note a data adjustment for month-end effect.

\section{Data adjustment for month-end effect}

The nature of the chosen data set requires adjustment for end-month trading dynamics; that is, the difference between the fundamentals driving the price of the futures in one month compared with the fundamentals driving the price of the futures for the subsequent month. This shift can be observed on the last trading day of the month which is, in fact, the first day of trading of the following month's futures in our data set according to the NYMEX trading rules. As a result, the 
difference in the fundamentals can be seen in the often significant increase/decrease in the price on that day.

In Figure 8, the volatility calculation adjusted to avoid the month-end effect is shown as the red line. From the figure, the red line often has lower peaks than the green line, which represents the unadjusted calculation. Figure 9 demonstrates that this effect is most pronounced in the months of September and October, when the largest shift in fundamentals generally occurs.

It can be argued, however, that the shift in fundamentals is, in fact, reflective of the true underlying volatility. This is due to the fact that at the end of the month (at contract expiration) the NYMEX WTI contract converges to the spot price of WTI, while the Brent ICE Future converges to the ICE Futures Brent Index (unlike the WTI contract, the Brent contract is not a physical one). ${ }^{15}$ Therefore, in the paper, where possible we use the original data set for each commodity. The data set adjusted for the month-end effect, if used, will be referred to as the "controlled" data set.

Figure 8: Henry Hub front-month original and controlled volatility

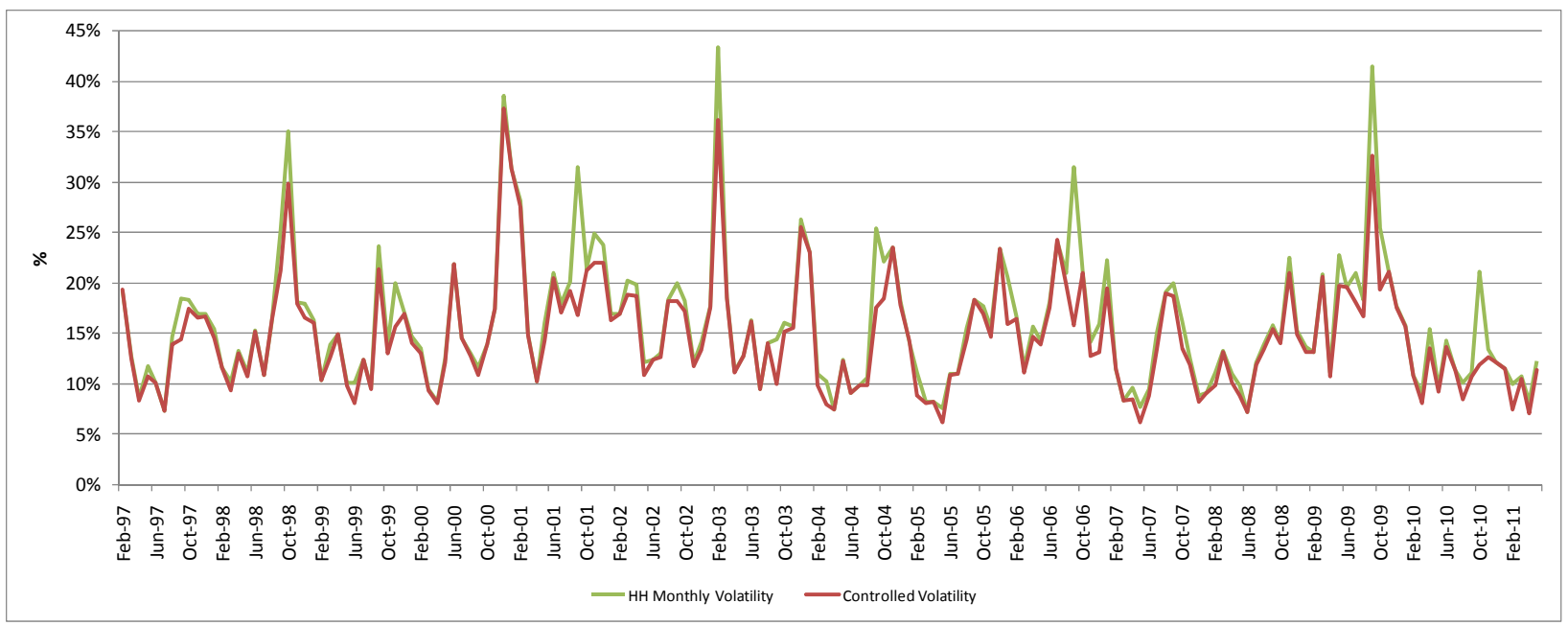

Source: Author's own analysis

Returning to the seasonality point mentioned earlier, the figure below illustrates the seasonality of the natural gas price volatility using both the original and controlled data set. The difference between the two data sets is greatest in the months of September and October, where the original data and controlled data graphs decouple.

\footnotetext{
${ }^{15}$ Fattouh 2010, p 4
} 
Figure 9: Henry Hub average monthly price volatility 1997 - 2010: original and controlled

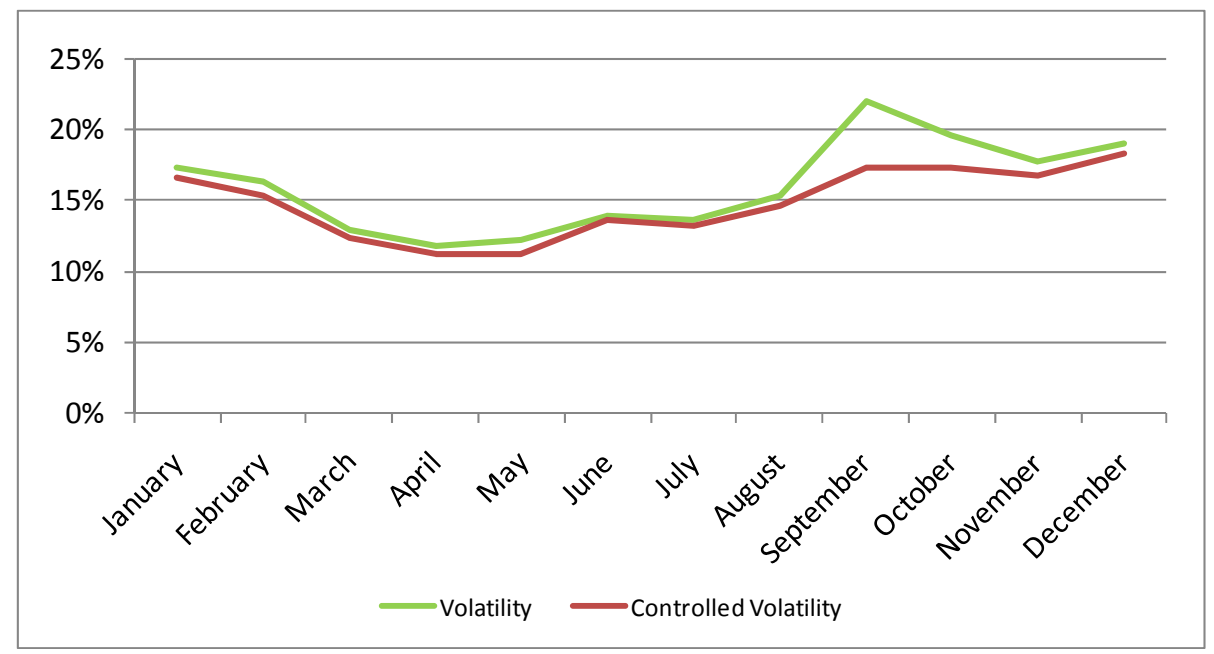

Source: Author's own analysis

\section{Factors affecting natural gas fundamentals and volatility in the US}

As a liberalized market, the natural gas market in the US is largely affected by factors related to the supply or demand for this commodity. However, the behaviour and volatility of natural gas prices in the US is often attributed to speculative activity in the financial markets for natural gas. While this argument may have merit, it is beyond the scope of this paper. The section below focuses on examining and explaining the factors affecting natural gas fundamentals. Several factors appear as the leading causes of natural gas volatility in the United States, all of which can be grouped broadly under the category of factors affecting the availability of supply. These are the presence of hurricanes, storage dynamics and imports. Demand factors, such as weather, also play an important role and are analyzed below.

\section{Factors affecting supply: hurricanes}

Figure 10 illustrates the United States Gulf of Mexico offshore natural gas production for the period from 1997 to 2011 as well as the corresponding monthly volatility of natural gas frontmonth futures (original data, unadjusted for month-end effect). The marked temporary drops in production (noted with orange boxes and arrows) indicate periods where significant offshore production was shut down, due to an impending hurricane. The graph shows that between 1997 and 2004 the front-month natural gas futures reacted to the shut-downs with a significant increase in volatility. 
However, starting in 2005, volatility response to hurricane-induced production drops decreased considerably. Below, periods of highest hurricane activity ${ }^{16}$ (corresponding to the numbered blue circles in the graph) and consequent natural gas front-month volatility are described.

Figure 10: US Offshore production (Gulf of Mexico) and major hurricanes

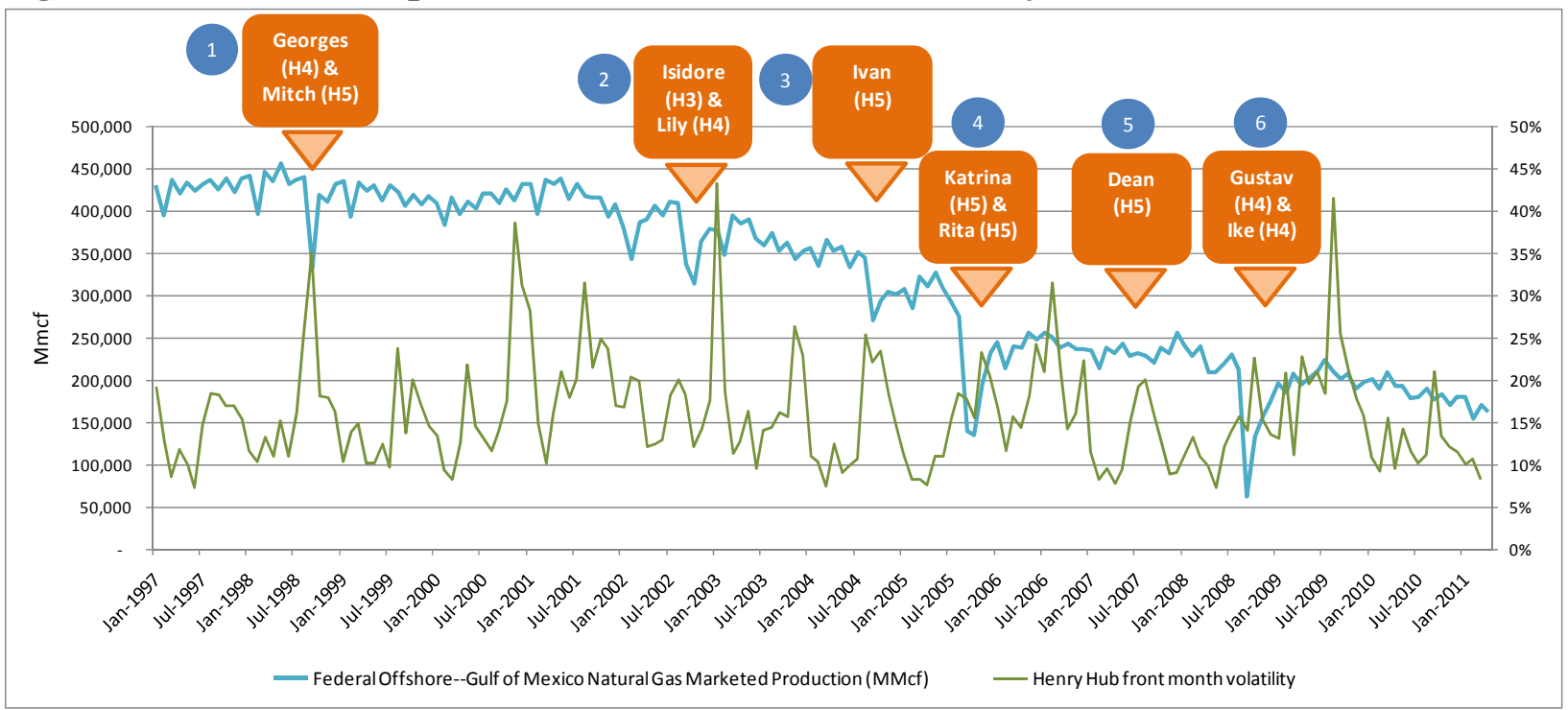

Source: EIA

1. In September 1998 Gulf of Mexico offshore production dropped approximately $20 \%$ and volatility increased to $25.2 \%$, increasing further to $35 \%$ in October as the hurricane season persisted with the arrival of Hurricane Mitch, one of the most powerful Atlantic hurricanes ever observed $^{17}$.

2. In September 2002, natural gas offshore production dropped $17.5 \%$, leading to an increase in volatility to $20 \%$. That was the second highest volatility period for the year, with the highest taking place in March 2002 at 20.3\%.

3. In September 2004, US Gulf natural gas production dropped by $21.6 \%$. Volatility for this month reached $25.4 \%$, the highest for the year.

4. In September 2005, offshore production fell off by $49.5 \%$ in the largest drop in offshore production up to that point, precipitated by the arrival of Hurricane Katrina - the costliest hurricane in US history. Yet volatility during this month amounted to only $18.4 \%$, second highest for the year, with the exception of December 2005.

\footnotetext{
${ }^{16}$ Category 4 and 5 only

17 Mitch: The Deadliest Atlantic Hurricane Since 1780' NOAA Satellite and Information Service.,http://www.ncdc.noaa.gov/oa/reports/mitch/mitch.html
} 
5. In 2007, Atlantic Hurricane Dean, though a powerful category 5 hurricane, produced moderate disruption in the offshore Gulf of Mexico production. Natural gas production fell 10\%. The volatility of the front-month natural gas contract rose to $19 \%$ and $20 \%$ in August and September respectively.

6. In September 2008, US natural gas offshore production experienced its biggest disruption yet when production for the month dropped by $70.8 \%$, recovering in October by $100 \%$. While such significant fall in production would be expected to produce uncertainty in the markets and higher volatility, the volatility response was in fact noticeably limited. Volatility for September 2008 was $15.7 \%$, still second highest for the year, however, as 2008 was characterized by low volatility in general. The graph below illustrates the scale of production disruption in 2008 compared to prior years.

Figure 11 illustrates the changes in offshore production in percentage terms (in place of the absolute levels which are shown above). The graph demonstrates that between 2005 and 2011 the impact of hurricanes on offshore production increased substantially, affecting a greater percentage of total offshore gas production.

\section{Figure 11: Monthly \% change in Gulf of Mexico marketed production}

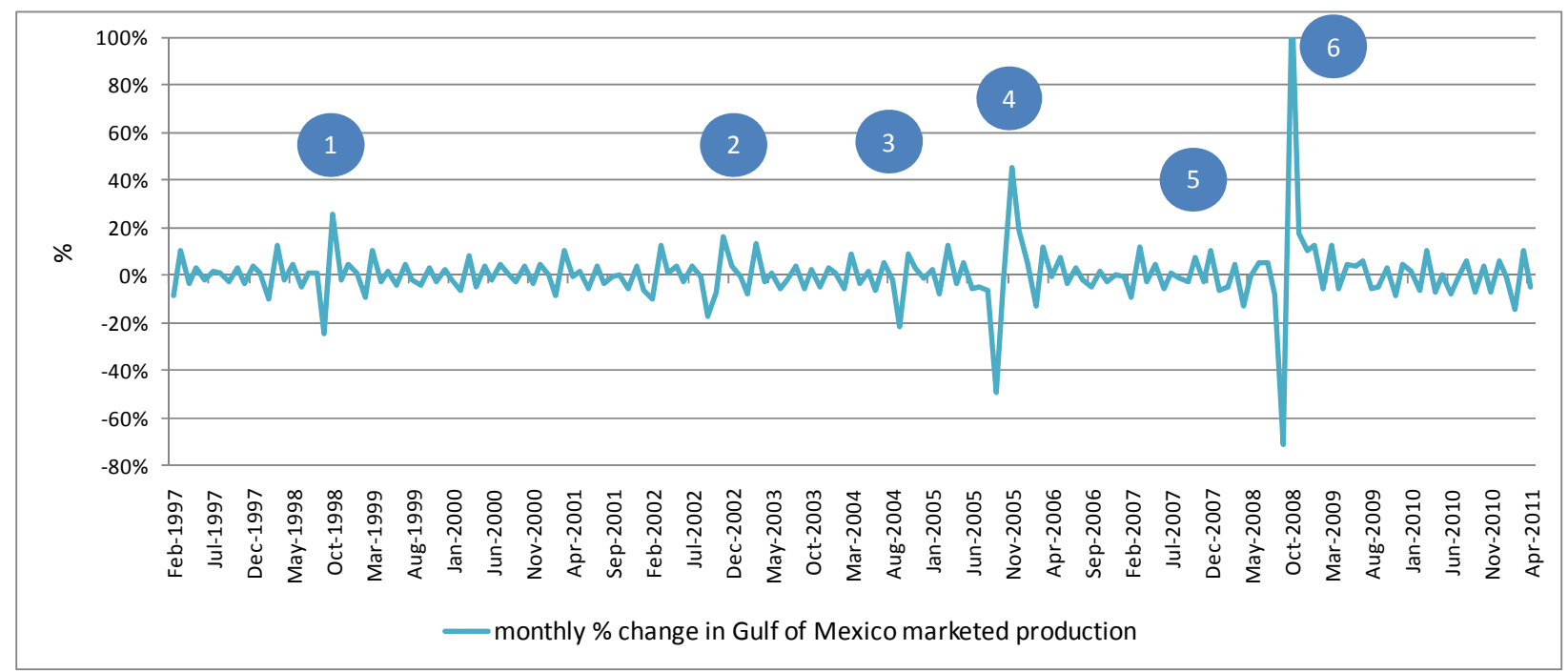

Source: Author's own analysis, based on EIA data

Several key conclusions can be drawn from the above analysis. First, the natural gas market showed greater sensitivity to disruptions in offshore production between 1997 and 2001, when offshore production constituted approximately $27 \%$ of total domestic production ${ }^{18}$. Second, the rapid decline in offshore production that started in 2001 led to a decrease in hurricane related price volatility of natural gas front-month futures.

\footnotetext{
${ }^{18}$ EIA data, author's calculation.
} 
Today, offshore production constitutes less than $10 \%$ of US total natural gas production ${ }^{19}$. Due to its diminished relative scale, offshore production no longer has the same impact on the natural gas markets. Starting in 2004, natural gas price volatility became less sensitive to the major hurricane-induced production disruptions, despite these disruptions becoming more severe. And with the advancement of shale gas, beginning in 2005, the volatility response declined further as the abundance of supply and expectations of continued supply plenty left the market less concerned with possible offshore production outages.

\section{Storage}

Due to the relatively isolated nature of the US market, its storage capacity acts as an especially important balancing instrument. Its levels are reported weekly and followed closely by the analyst community as it is often seen as a demand indicator. Storage levels rise gradually to peak in October - the last storage-filling month before winter advances. While weather predictions play an important role in estimating a particular winter's demand, the natural gas community often finds itself surprised by the onslaught of colder or warmer than expected weather, so creating uncertainty in the market.

\section{Figure 12: US working natural gas in storage actual compared with five-year average}

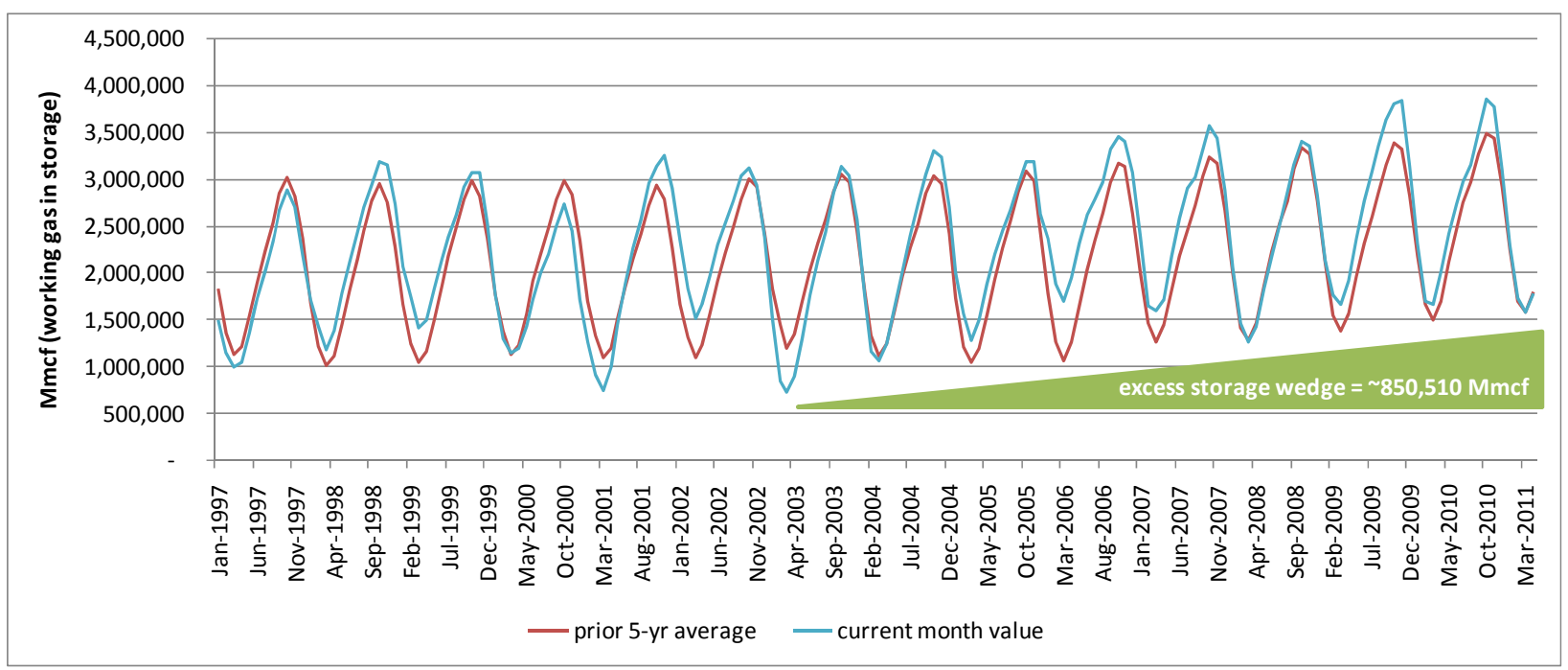

Source: Author's own analysis, based on EIA data

Figure 12 shows a comparison between a five-year average of storage levels and actual storage levels from January 1997 to March 2011, where annual peaks represent storage available at the beginning of the winter and annual lows represent the level of storage at the beginning of the storage filling season. Consequently, in terms of impacting market behaviour, the critical storage levels to observe are those during the winter space heating season and those at the end of the injection season (September/October).

\footnotetext{
${ }^{19}$ EIA data, author's calculation.
} 
Referring to Figure 12, winters with below average storage inventory signify colder than usual winters and should therefore, we hypothesize, produce higher volatility. Given that the supply of natural gas at the beginning of the winter is essentially fixed, any unanticipated change in demand such as an onslaught of cold weather, especially in the early winter months, generally produces uncertainty in the market related to supply adequacy concerns, leading to increased volatility.

From Figure 12, the winters of 2000/2001 and 2002/2003 showed storage levels significantly lower than the five-year average. As might be expected, the volatility during January 2001 and January 2003 reached $31 \%$ and $43 \%$ respectively - the highest winter months' volatility for the period considered.

The winters of 1998/1999 showed storage levels significantly higher than the five-year average and the volatility for the period remained below $20 \%$. However, during the winter of 2001/2002, despite mild weather, volatility increased to above $20 \%$. This may have been due to the increased uncertainty brought on by the Enron bankruptcy filing in November 2001 - an exogenous event that, while having no impact on the fundamental supply and demand of natural gas, still produced considerable uncertainty in the market.

Starting in 2005, winter storage levels stayed above the five-year average, in part resulting from milder weather (see Figure 14, Winter weather and average winter volatility) but also due to the increased availability of shale gas in the US contributing to a lower volatility for these winter months.

2006 was characterized by mild and warmer than usual weather throughout the year, leading to abundant levels of natural gas in storage. With storage levels at 3.177 Tcf in September 2006 or close to the ten-year high of $3.327 \mathrm{Tcf}$, the front-month contract fell to a two and a half- year low, creating significant volatility that was $21 \%$ in August and $31.5 \%$ in September. ${ }^{20}$ Underlying this high volatility were the fears of storage inventory reaching maximum physical capacity, which could have resulted in natural gas well shut-ins if the gas price declined materially.

\section{Import capacity}

As shown in Figure 13, between the mid-1980s and 2000s, US natural gas imports rose significantly - from 5\% of consumption in 1986 to $16 \%$ in 2001 as domestic demand increased. However, since the advance of domestic unconventional gas production, mainly of shale gas, US imports began to decline again and in 2010 constituted less than $11 \%$ of total consumption, or the lowest level since 1992. This figure includes both pipeline imports from Canada and LNG imports. Between 2007 and 2010, US LNG imports declined by 50\% while pipeline imports

\footnotetext{
${ }^{20}{ }^{N}$ Natural-gas futures end at a two-and-a-half year low', The Wall Street Journal, Sept. 21, 2006 http://www.marketwatch.com/story/natural-gas-futures-end-at-a-two-and-a-half-year-low-oil-gains
} 
declined by $28 \% .^{21}$ The growing importance of shale gas in US natural gas consumption has rendered other sources of natural gas far less critical for the time being.

\section{Figure 13: US natural gas consumption by origin ${ }^{22}$}

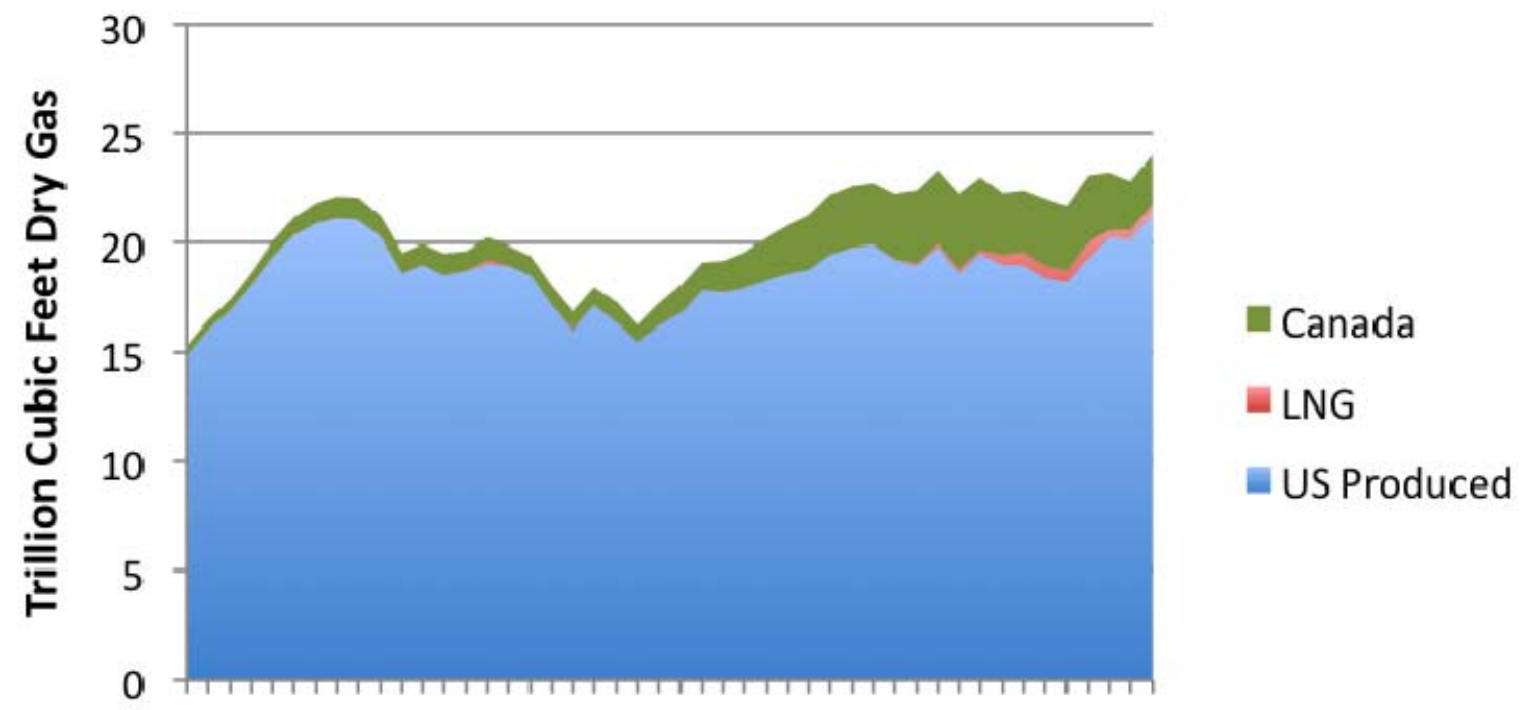

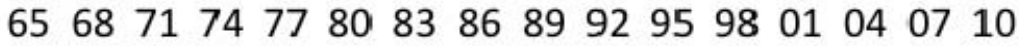

Sources: US EIA, Annual Energy Outlook 2010

\section{Factors affecting demand: weather}

Natural gas demand is largely driven by weather. Other factors affecting natural gas demand in the US are GDP growth (leading to lower or higher demand) and efficiency gains (leading to lower demand). However, these factors affect natural gas demand over a period of months or even years and have little impact on month-to-month volatility ${ }^{23}$.

Figure 14 illustrates the relationship between winter weather and the natural gas volatility. The bars (red and blue) indicate the difference between the heating degree days in a given year and the average heating degree days from $1997-2010 .^{24}$ The red bars represent winters ${ }^{25}$ with warmer than average temperatures. The blue bars represent winters with colder than average

\footnotetext{
${ }^{21}$ EAl, 'Today in Energy, April 1, 2011, http://www.eia.gov/todayinenergy/detail.cfm?id=770

22 'Energy Outlook', December $15^{\text {th }}$ 2010, http://energyoutlook.blogspot.com/2010/12/natural-gas-and-gulfhiatus.html

${ }^{23}$ Other than during a recession when rapidly falling GDP may accompany high price volatility.

${ }^{24}$ Heating degree day (HDD) is calculated as the number of degrees that a day's average temperature is below 65 degrees Fahrenheit - the temperature below which buildings need to be heated. http://www.investopedia.com/terms/h/heatingdegreeday.asp\#axzz1f35d94yB

${ }^{25}$ Winter months: November, December, January, February, March
} 
temperatures. The green line shows the average level of volatility for the winter months of a given year.

Figure 14: US winter weather and average winter volatility 1997 - 2010 (red bars = warmer than average, blue bars = colder than average)

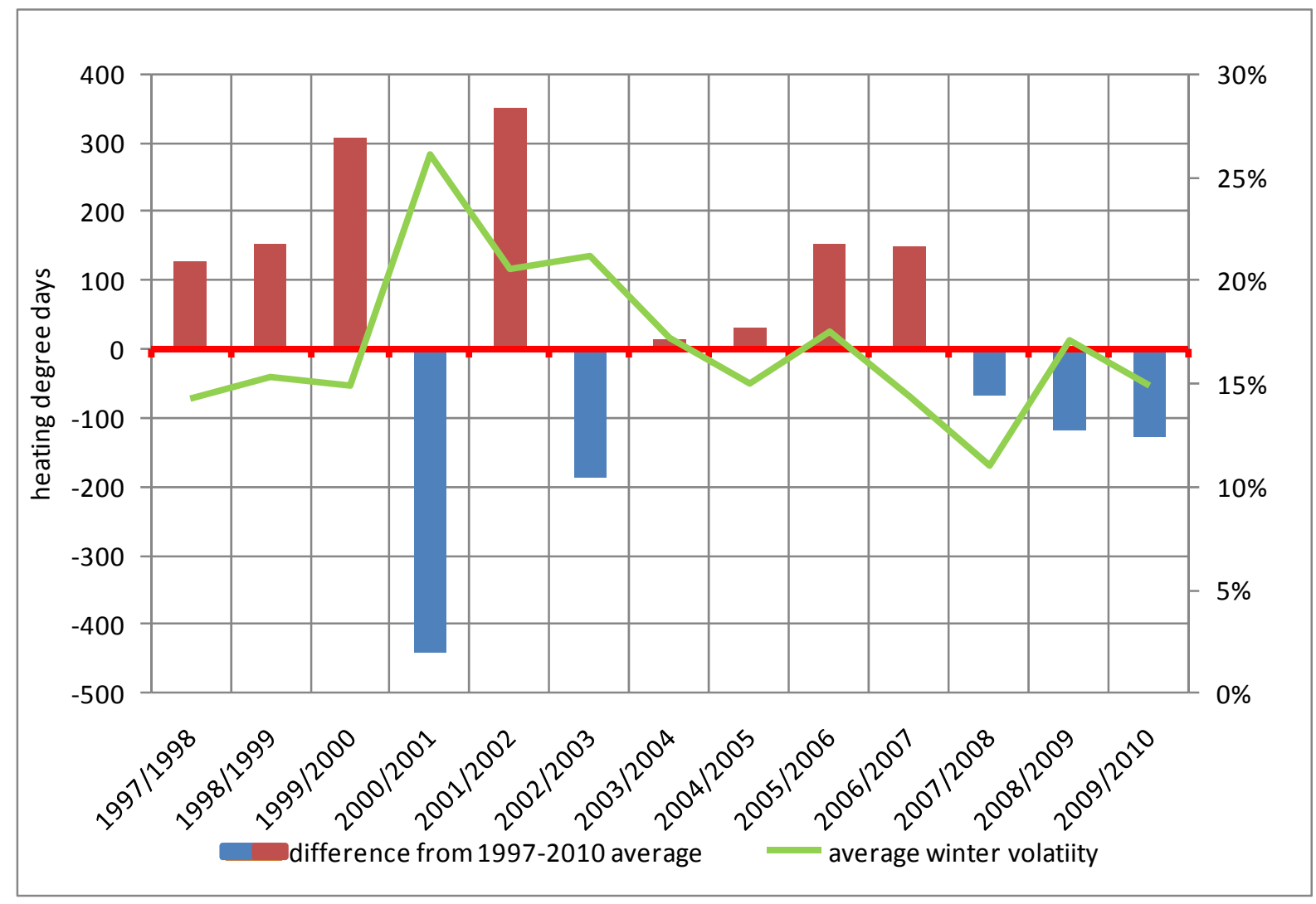

Source: National Climatic Data Center, NOAA,, Author's own analysis

Figure 14 shows that winter volatility stayed relatively low at around $15 \%$ during the first three winters of the period, all three of which were warmer than usual. During the winter of 2000/2001 with early cold temperatures, (in November and December), the volatility increased sharply to $26.1 \%$. The next cold winter was that of 2002/2003 which also produced an increase in volatility to $21.2 \%$. The following four winters from 2003 to 2007 were slightly warmer than average and volatility during this period stayed on average around $16 \%$. The last three winters in our observation period have been somewhat colder than usual. However, the volatility during this period was on average around $14 \%$ - an inconsistent phenomenon given our previous cold winter observations.

The reason behind this inconsistency was the change in the overall supply dynamic in the US natural gas market during the observation period. In fact, our observation period can be divided into two distinct periods characterized by a very different set of supply expectations and realities. 
Since 2006, U.S. natural gas markets have experienced a radical turnaround brought on by the expansion of production of unconventional natural gas resources. In the early 2000 s, with US domestic production in decline, the oil and gas majors were focusing on the investing in international LNG projects. At the same time, the US and Canadian independents that lacked the capital and global footprint to engage in such capital intensive international projects were working on innovative development strategies for unconventional gas. ${ }^{26}$ The result of their efforts was a rapid technological improvement in the shale gas production process, which led to a considerable and continuous decrease in the cost of production from shale assets. In the environment of high natural gas prices of 2007 and 2008 when Henry Hub spot prices reached $12.7 \$ / \mathrm{mmBtu}$ in June 2008 , more shale assets became economical to extract attracting new players into the arena and bringing on a wave of drilling and investment.

Starting in July 2008 , however, the Henry Hub spot price began to fall, to $3.50 \$ / \mathrm{mmBtu}$ in April 2009 and to a low of $3.01 \$ / \mathrm{mmBtu}$ in September 2009. While the prices remained low through mid-2011, this did not prevent the ongoing shale exploration and drilling from contributing to a significant expansion of domestic supply available for consumption and storage. Figure 12 illustrates this more specifically by showing the growing wedge of working gas in storage which is likely to remain surplus to winter space heating requirements for an indeterminate period.

\section{Notable volatility peaks}

Having analyzed the factors driving the price volatility of natural gas in the US, it is now possible to apply this framework to explain volatility episodes and peaks during the observed period (Figure 15).

1. 1998 October (35\%) - Hurricane Mitch (Category 5) threatened the Gulf offshore production. Front-month Henry Hub price increased by $6 \%$ in one day on October $27 .{ }^{27}$

2. 2000 December (38.5\%) - United States experiences the second coldest November on record since 1895, followed by record cold December. Prices of front-month gas contracts rose from $4.49 \$ / \mathrm{mmBtu}$ at the end of October to $6.59 \$ / \mathrm{mmBtuby}$ November 30 and $9.78 \$ / \mathrm{mmBtu}$ by December $29 .{ }^{28}$

3. 2001 September $(31.4 \%)$ - the $9 / 11$ terrorist attacks on United States brought about a global expectation of recession sending prices plummeting.

\footnotetext{
${ }^{26}$ Rogers, 2010. pp. 7,8

27 'Oil \& gas fueled by Hurricane Mitch 10-26-98', The Wall Street Journal, Oct 26, 1998, http://www.marketwatch.com/story/oil-gas-fueled-by-hurricane-mitch-10-26-98

${ }^{28}$ Climate-Watch, December 2000, National Oceanic and Atmospheric Administration, http://www.ncdc.noaa.gov/oa/climate/extremes/2000/december/extremes1200.html
} 
Figure 15: Henry Hub spot prices and monthly volatility

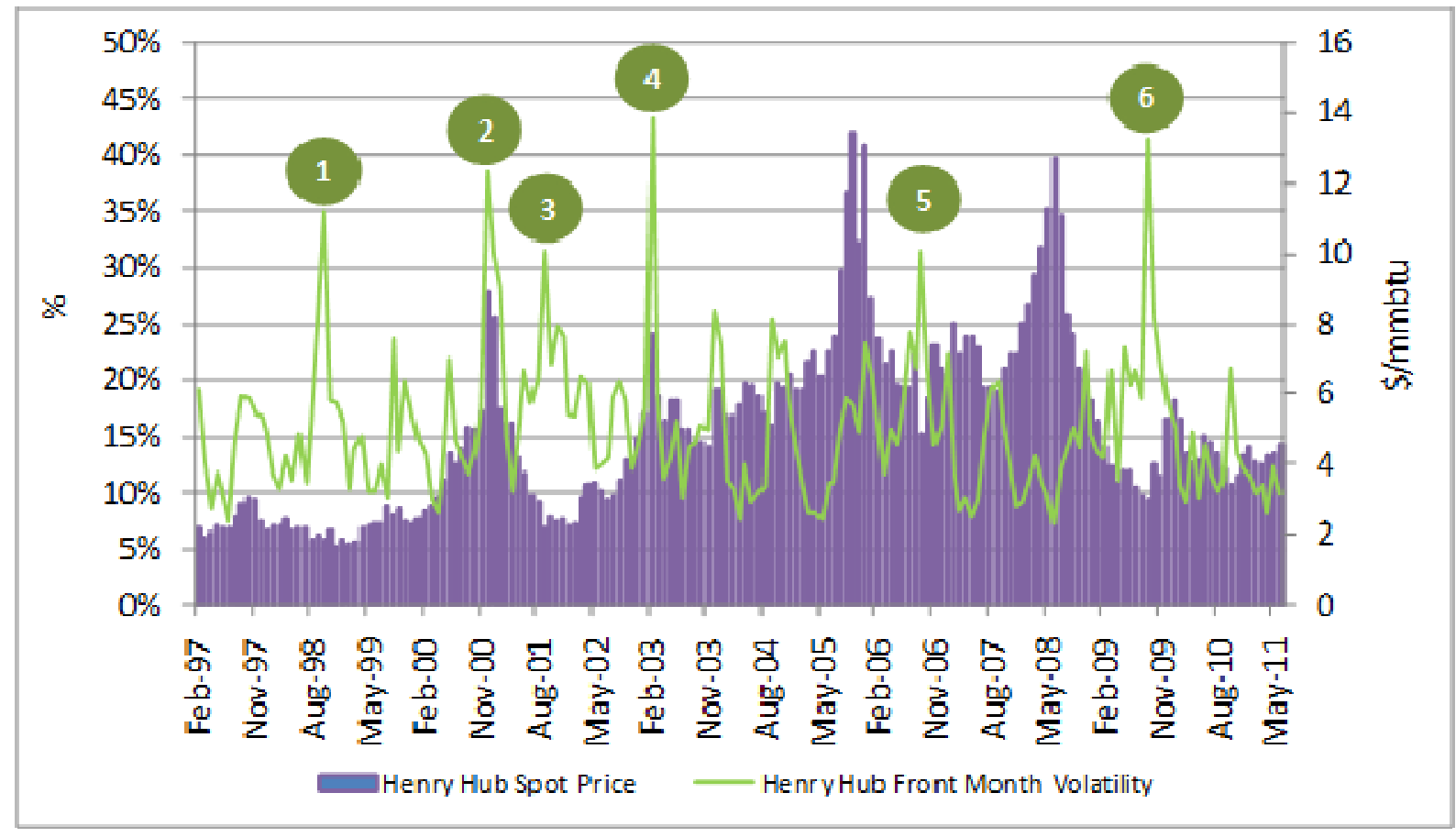

Sources: EIA, Author's own analysis

4. 2003 February (31.5\%) - Late winter cold weather brought about uncertainty over the availability of necessary supplies as the inventories were already low and, moreover, weather froze off producing wells. ${ }^{29}$

5. 2006 September (31.5\%) - Consumption declined to its lowest level since 1994 due to a warmer than usual winter. Production increased due to shale. In September 2006 - the highest gas rig count ever was recorded. On September 14 the EIA reported a three-digit gas storage injection for the first time since June $2005 .{ }^{30}$ Prices dropped dramatically as the market feared production shut-ins. In addition, Amaranth Advisors, a trading company, collapsed in September 2006 after losing $\$ 5$ billion on natural gas futures.

6. 2009 September (41.5\%) - natural gas storage approached capacity constraint as facilities around Cushing, Oklahoma, filled nearly to capacity due to mild summer heat and continued demand depression stemming from the 2008 global financial crisis. ${ }^{31}$

\footnotetext{
${ }^{29}$ Report on the natural gas price spike of February 2003, FERC, July 23, 2003, p.3.

30 'Natural Gas Futures Prices Hit 2 Year Low', The Oil and Gas Journal, September 25, 2006, http://www.ogj.com/articles/print/volume-104/issue-36/regular-features/market-journal/natural-gas-futuresprice-hits-2-year-low.html

${ }^{31}$ 'Storage growth to keep natural gas off lows', FT, September 9, 2010

http://www.ft.com/cms/s/0/2355287c-bc13-11df-a972-00144feab49a.html\#axzz1VknOdGjY;
} 
It is important to note here that several events occurred during the 1997 to 2011 period that one might expect to have produced high levels of volatility and yet these were not observed in the time series. For example, Hurricane Katrina, the most damaging and costliest hurricane in US history $^{32}$ produced volatility of only about $15.5 \%$ in August 2005. Similarly, Hurricanes Gustav and Ike, both Category 4 hurricanes, contributed to the largest drop in offshore production, when $95 \%$ of natural gas capacity was shut down, but produced a volatility of only $15.7 \%$ in September 2008.

The analysis suggests that the low natural gas volatility response to Hurricane Katrina was due to the gradual increase of the Henry Hub price in anticipation of the hurricane and the subsequent fall in demand which offset the production outages. With respect to Hurricanes Gustav and Ike in 2008, as mentioned earlier, by this time US was experiencing strong shale gas production growth. In an environment of such plentiful supply, the offshore production outages related to the two hurricanes had very little impact on the overall market fundamentals and therefore little impact on prices.

\footnotetext{
32 'Hurricane Katrina - Most Destructive Hurricane Ever to Strike The US, August 28, 2005, National Oceanic and Atmospheric Administration. http://www.katrina.noaa.gov/
} 


\section{Patterns and episodes in natural gas price volatility - NBP}

\section{Overview}

The National Balancing Point (NBP) is the trading hub for UK natural gas and is the pricing and delivery point for the Intercontinental Exchange (ICE Futures Europe) natural gas futures contracts. Unlike the Henry Hub, NBP is a virtual trading hub ${ }^{33}$. Figure 15 shows the price volatility of NBP front month gas delivery contracts over the period from 1997 to 2011.

\section{Figure 16: NBP price volatility (original)}

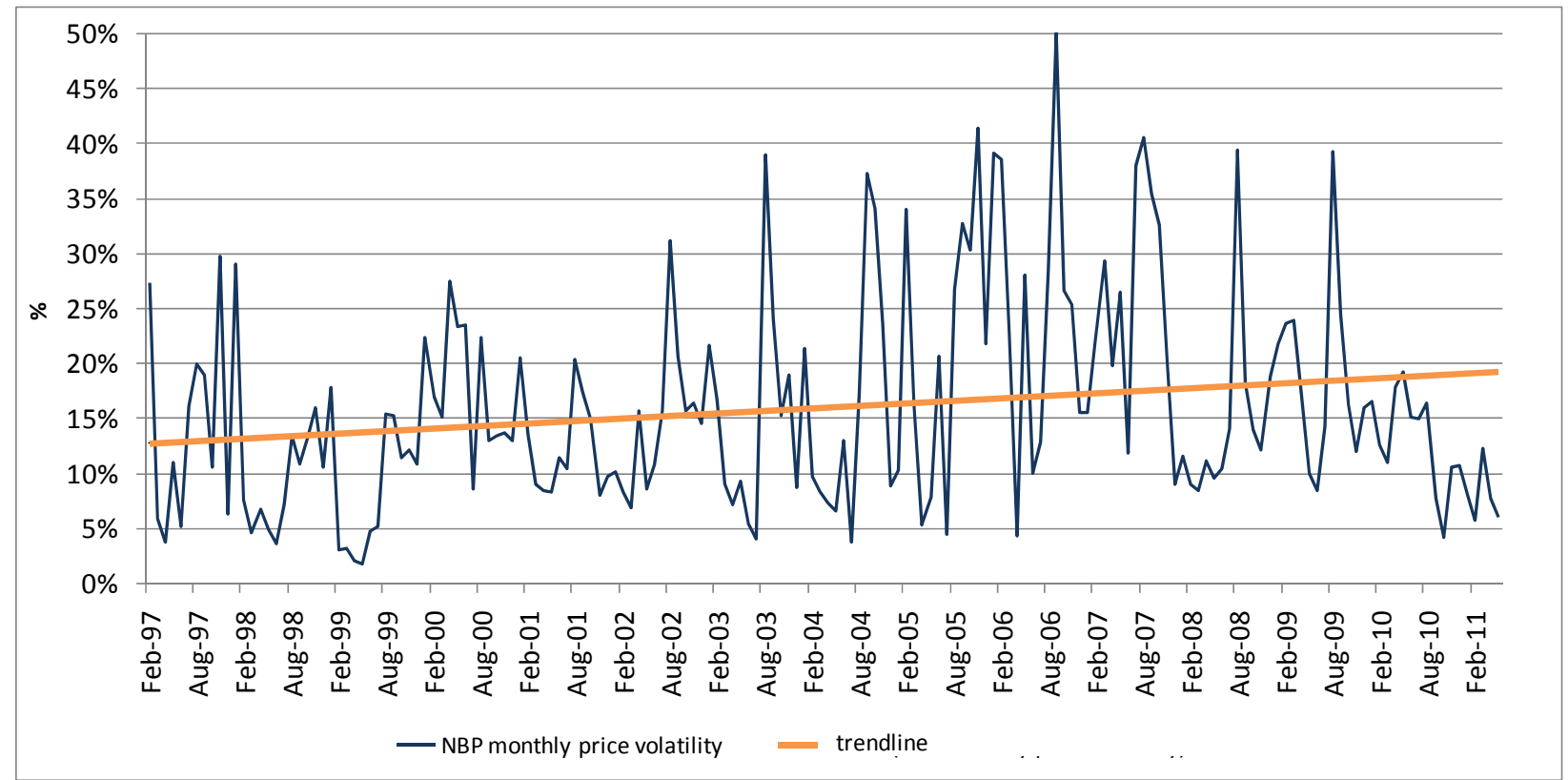

Sources: ICE, Author's own analysis

The following observations can be made from examining Figure 16:

1. There is a distinct increase in volatility starting around 2003, with peak volatility reaching $50 \%$ and minimum volatility moving from below $5 \%$ in the first part of the observed period to between $5 \%$ and $10 \%$ in the second half of the observed period.

2. There is also a distinct drop-off in volatility starting in the fall of 2009 . Volatility continues to fall through the first part of 2011.

3. Overall, the linear trend line shows significant increase in volatility for the period from approximately $14 \%$ to closer to $20 \%$ in 2011 .

\footnotetext{
${ }^{33}$ The whole of the UK is one entry-exit zone for natural gas trading; the NBP hub has therefore no physical point location.
} 
Before going further into the examination of NBP volatility it is important to address the data adjustment point similar to the one discussed above in Chapter 4 relating to Henry Hub.

\section{Data adjustment for month-end effect}

The underlying data is taken from the ICE exchange and represents the daily settlement value for the front-month natural gas futures traded on the exchange. The ICE exchange stipulates that the trading for the front-month contracts ceases on the second to last business day of the month. For example, the value for June 29 represents the price of the July contract, while the value for June 30 already represents the value for the August contract. As a result, the price volatility calculations based on the original data set produced a number of volatility spikes at month-end. These are due to the differences in the underlying fundamentals between the two future months. If the fundamentals of supply and demand have changed dramatically during the course of the month, then a disproportionate increase in volatility can be observed stemming from the price differences on the border days.

Figure 17: NBP price volatility (controlled)

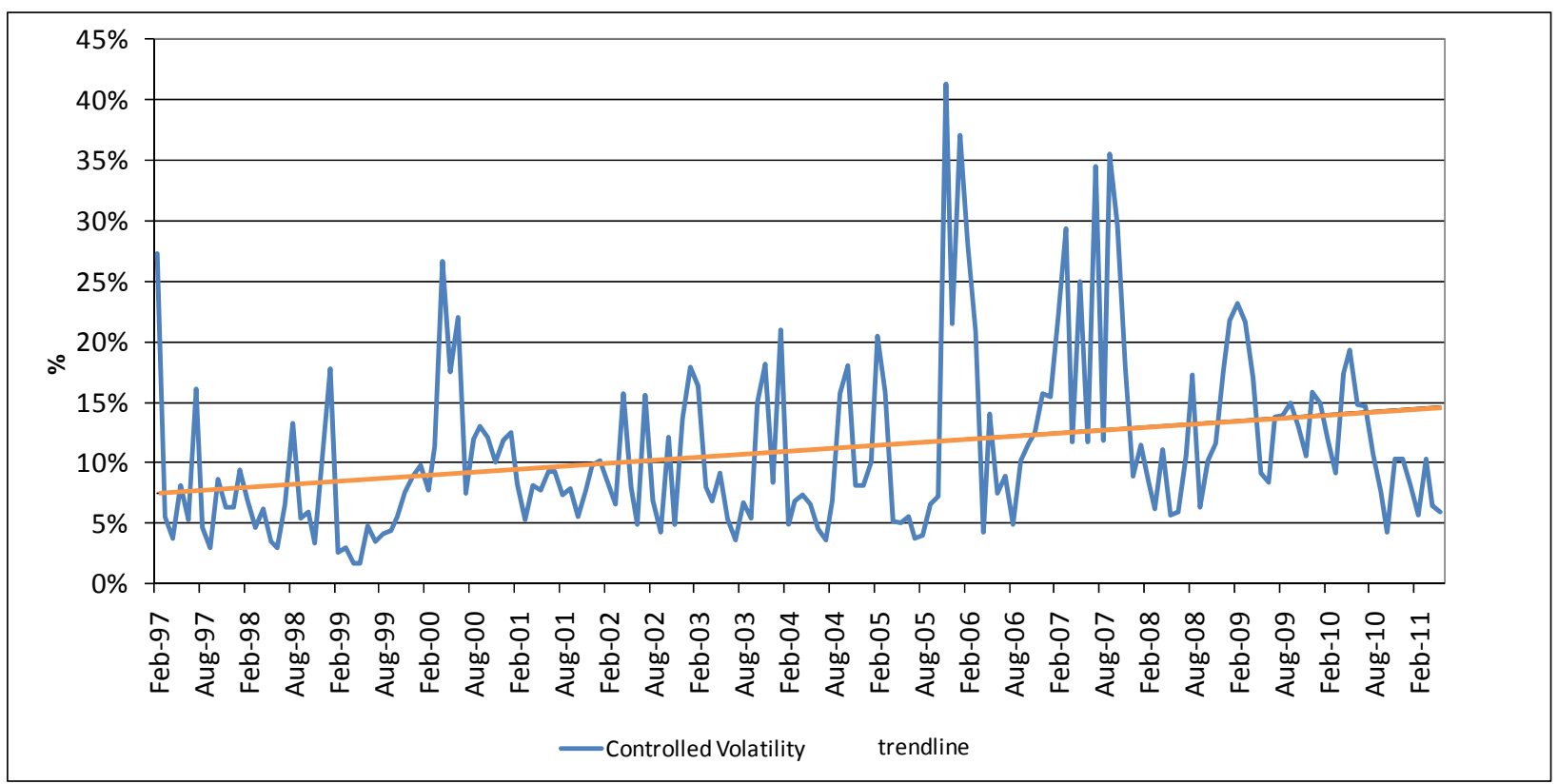

Source: Author's own analysis

In Figure 17, the price volatility of the 'controlled' data set exhibits patterns similar to those of the original data. However, the controlled volatility shaves off the volatility peaks caused by the month-end effect and presents a clearer picture of the evolution of the NBP price volatility over time. Again, similar to the original data, the controlled data set shows a rather steep upward sloping trend line, starting at approximately $8 \%$ in 1997 and ending at closer to $15 \%$ in 2011 . 
While it may be said that the original calculations represent the 'as reported' data, we consider the controlled data set as more representative in this case and free of 'noise'. The difference between the two sets is more pronounced for the NBP than is the case for Henry Hub. This might be due to the greater trading volume (and number of participants) in Henry Hub contracts and possibly the greater maturity of the US gas market.

\section{Understanding patterns and periods of increased NBP price volatility}

As in the US, as a liberalized market the UK gas market is one where price is primarily governed by the interaction of supply and demand. Thus the main drivers for volatility in this market should be the factors influencing supply availability and demand dynamics. Using this hypothesis, we will consider several of these factors.

\section{Demand factor: weather and seasonality}

The majority of natural gas consumption in the UK is in the space heating and power generation sectors and therefore it should exhibit seasonal variation generally similar to the US. Analysis of the 'controlled' NBP volatility data set indeed found that to be the case - substantial differences in volatility exist between winter months when gas is used heavily and demand shocks, stemming from unexpected cold weather, are frequent. On average, the winter months (November through March) between 1997 and 2011 produced a volatility of $13.0 \%$, while the balance of the year produced an average volatility of $9.9 \%$. Figure 18 illustrates these results graphically.

Figure 18: Seasonal variation in NBP monthly volatility 1997 - 2010

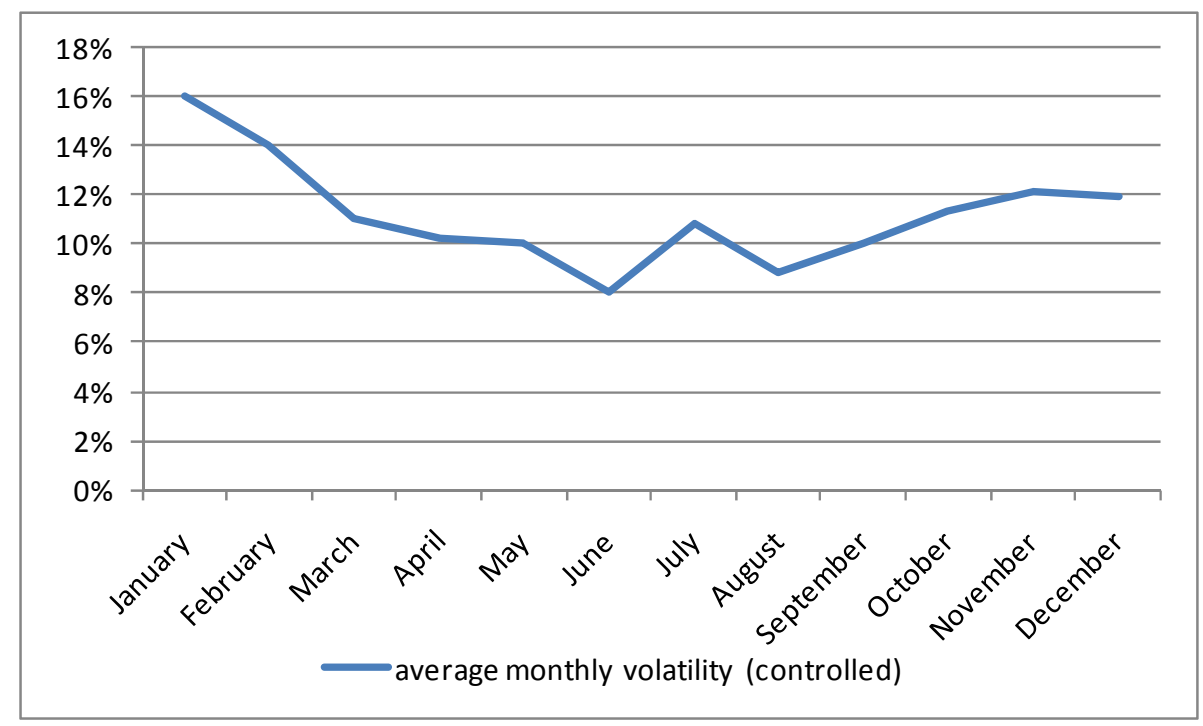

Source: Author's own analysis 


\section{Supply factor: storage}

Storage is generally seen as a source of flexible gas that can be relied upon in the event of sudden surges in demand. The UK market differs radically from the US market in terms of availability of storage. As of May 2010, the UK market had $4.3 \mathrm{Bcm}$ of storage capacity, representing approximately $4 \%$ of its annual consumption compared with $18 \%$ of annual consumption in the US. Moreover, UK storage is highly concentrated - of the $4.3 \mathrm{Bcm}$ of total capacity, $3.3 \mathrm{Bcm}$ is provided by one storage unit, the Rough facility in the Southern North Sea operated by Centrica Storage Ltd. The relatively low aggregate storage capacity in the UK is due to the historical ability of domestic fields to vary production levels to provide seasonal supply flexibility. As UK gas production declined post-2000, very little investment in new storage capacity took place to offset the reduction in production flexibility. As a consequence, the UK gas market experienced a supply shock when in February 2006, with several more weeks of winter to come, a fire at the Rough facility caused it to be taken offline. No gas withdrawals were possible and repairs continued through June 2006. This led to a sharp increase in prices and a similarly steep increase in volatility.

\section{Supply factor: import capacity}

Due to the low provision of storage capacity in the UK, other sources of supply flexibility are needed to meet the country's seasonal variation in gas demand. Variations in import flows provide a significant source of such flexibility and play an important role in determining the availability of supply to the UK customers. As the UK transitioned to becoming a significant gas importer, import flow variations also became a key driver of volatility in the country's natural gas prices.

Figure 19 illustrates all import flows into the UK from February 1997 to April 2011 and shows that, starting in 2001, as production from domestic gas fields began to fall off, UK winter imports of gas increased substantially. Between 2001 and 2003 these were largely pipeline imports from Norway. Starting in the winter of 2003/2004, the UK also began to rely on IUK ${ }^{34}$ imports from Belgium to fulfil some of its seasonal demand. However, in 2005 the onset of cold weather early in the winter season (November) resulted in European suppliers being reluctant to release gas from storage in order to ensure that Public Service Obligations could be met for the rest of the heating season. ${ }^{35}$ This led to considerable volatility in the UK gas markets.

\footnotetext{
${ }^{34}$ IUK - the UK to Belgium bi-directional interconnector pipeline.

${ }^{35}$ Rogers 2011.
} 
Figure 19: UK imports $1997-2011^{36}$

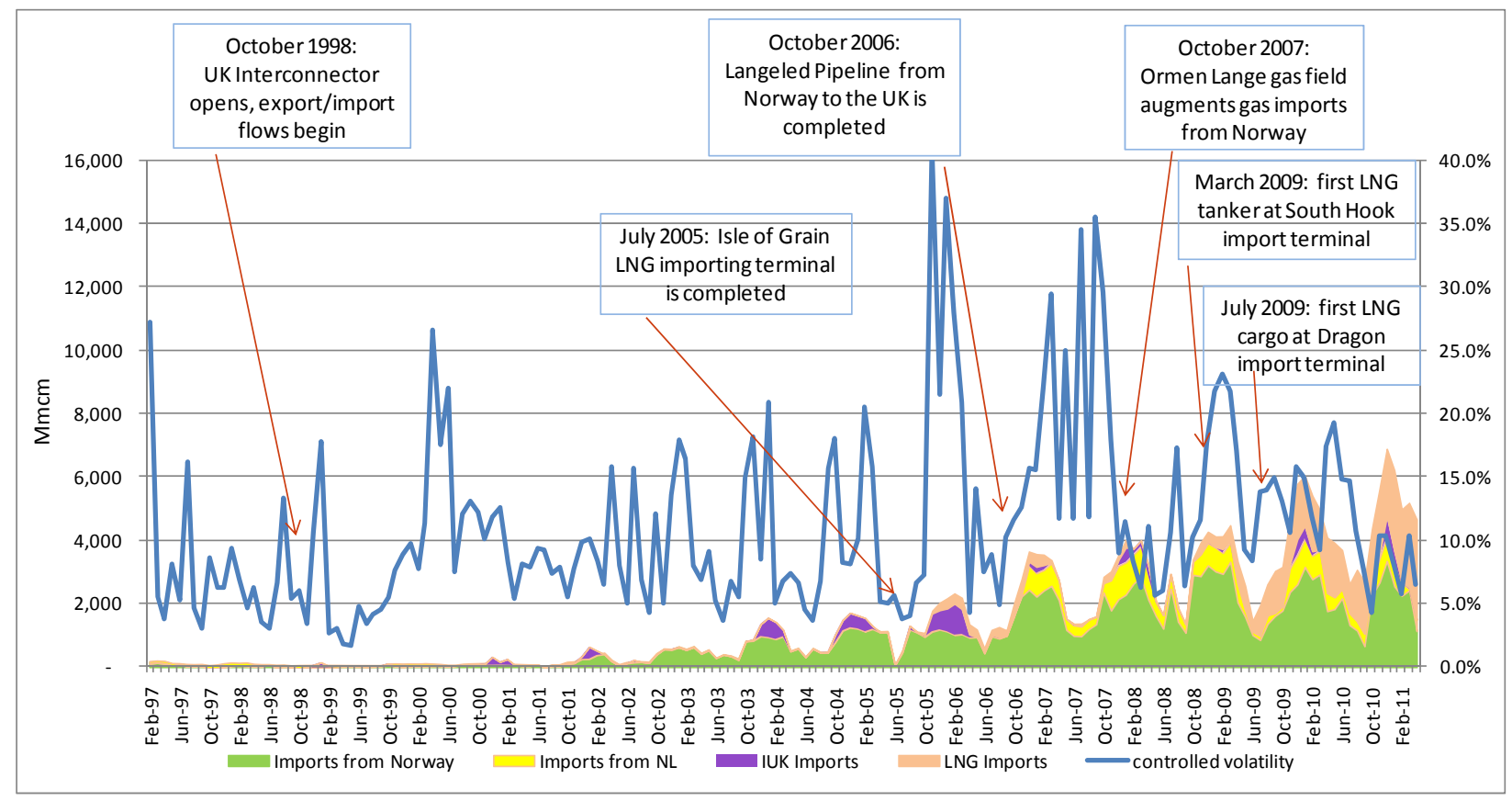

Source: DECC, Waterborne LNG, Author's own analysis

The period between November 2005 and November 2007 is characterized by unprecedented volatility levels brought on by a confluence of events: unusually cold weather in November 2005, the Russia/Ukraine conflict in January 2006 and the Rough storage outage in February 2006. The summer and winter of 2006 was a relatively low volatility period, characterised by the availability of LNG from the Isle of Grain and an absence of exogenous events.

Starting in January 2007, as prices began to fall with the opening of the new Langeled pipeline from Norway, volatility increased sharply. The UK gas market was suddenly faced with an oversupply of natural gas that it could not easily absorb due to the lack of storage capacity. As a result, prices continued to drop sharply through July 2007, a trend which reversed when an outage of the CATS UK import pipeline led to supply concerns.

The period starting in December 2007 was characterized by abundant supply and generally lower volatility. With the onset of the global financial crisis in October 2008 and a decrease in global demand for gas, more LNG began to arrive in the UK. During this period several major LNG supply facilities came online in Qatar, Yemen and Nigeria, ${ }^{37}$ just as Asian LNG demand declined and the need for US LNG imports was limited due to strong shale gas production

\footnotetext{
${ }^{36}$ Milford Haven's Dragon LNG to receive first shipment, Western Telegraph, July 14, 2009, http://www.westerntelegraph.co.uk/news/localnews/milfordhaven/4490805.First shipment to arrive at Dragon LNG/; http://www.hydrocarbons-technology.com/projects/grainlngkent/\#

${ }^{37}$ Rogers 2010.
} 
growth. Thus the UK began to receive unprecedented volumes of LNG, resulting in low UK prices, starting in January 2009.

As available supply in the UK expanded, volatility fell and remained on average around $10 \%$, with the exception of an increase in volatility to $17 \%$ and $19 \%$ in April and May 2010 respectively. During these two months, LNG imports exceeded those during the same period in the previous year (2009) by $1 \mathrm{Bcm}$ and $1.4 \mathrm{Bcm}$ respectively, sending the UK price lower still. LNG imports continued to increase steadily through the end of our observation period, reaching $3.2 \mathrm{Bcm}$ by April 2011, thus creating an environment of abundant supply and low price volatility.

\section{NBP analysis conclusions}

As shown in Figure 19, the period from 1997 to 2011 can be divided into three periods, each characterized by a distinct natural gas supply dynamic that set the stage for the volatility observed.

Figure 20: NBP price and volatility

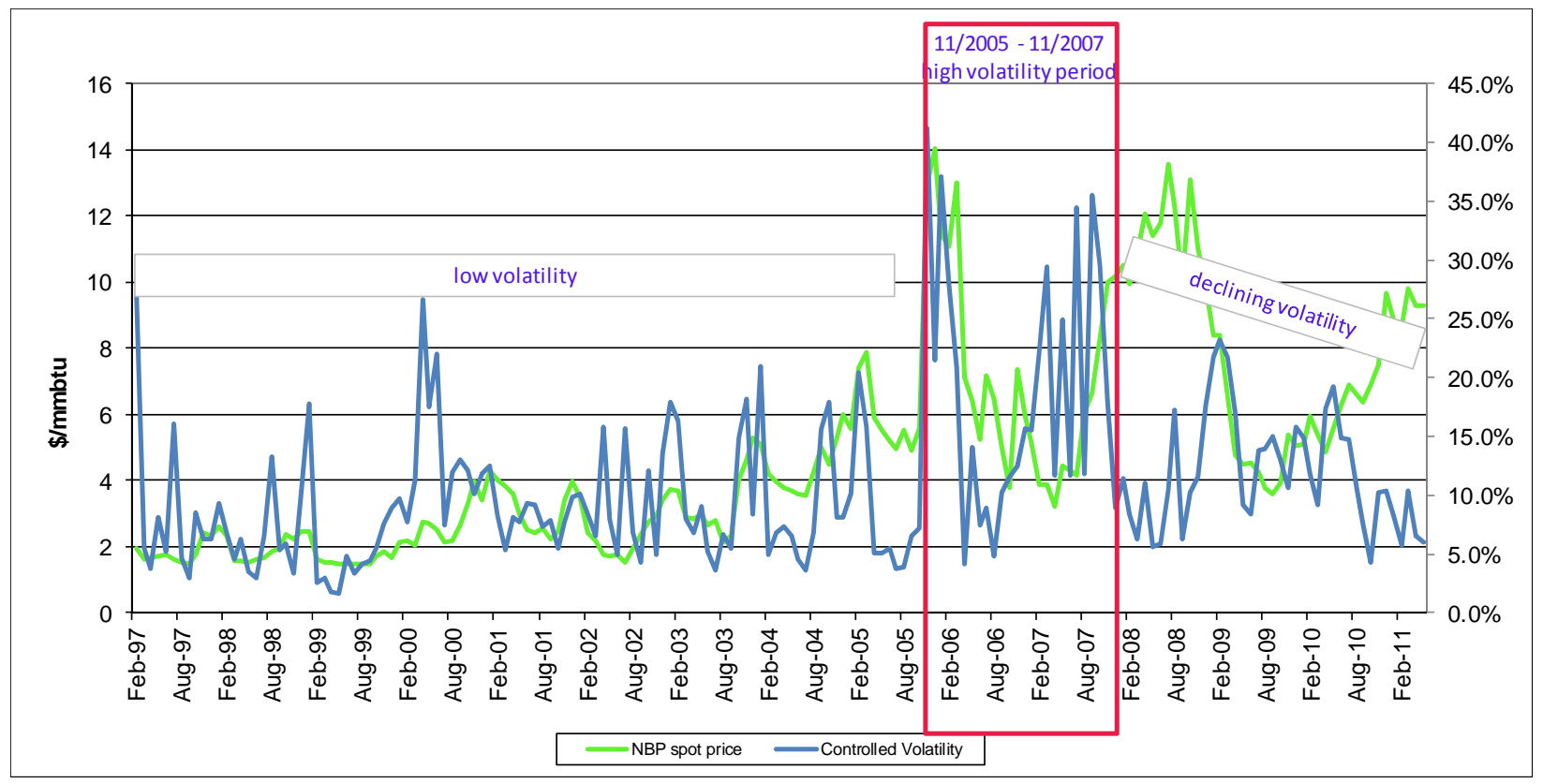

Source: Platts, Author's own analysis

1. 1997 - 10/2005 -- This period was characterized by a relative abundance of supply, resulting in the UK's becoming a net exporter once the Bacton-Zeebrugge interconnector pipeline became operational in 1998. However, domestic production peaked in 2000 and prices began a gradual rise as the UK market tightened. This tightening is also visible in the seasonal winter volatility peaks which become higher towards the end of the period. 
The highest volatility peak for this period was observed in April 2000 when it reached 26.6\%. This was largely due to a sudden increase in gas prices in the UK in response to the higher gas prices on the continent. The latter rose in the second half of 2000 as oil-indexed contracts adjusted to reflect the increase in oil prices which occurred during 1999. As oil-indexed contracts typically operate on a lag of between 6 to 9 months, it took until Q2 2000 for the gas prices to fully reflect the change in oil prices. ${ }^{38}$

2. $11 / 2005-11 / 2007$-- A number of factors during this period led to high volatility.

In November 2005 an early cold snap reduced domestic production flexibility. European producers were reluctant to release gas from storage, so UK imports were constrained.

In January 2006 a Russia/Ukraine gas contract stand-off escalated. Gazprom reduced gas flows to Ukraine due to the dispute. Some European customers failed to receive full volumes of gas over a $24-48$ hour period, escalating fears over supply. ${ }^{39}$

In February 2006 the Rough storage facility fire put a significant constraint on supply as no withdrawals were possible for the remainder of winter.

Between February 2007 and October 2007, warmer than expected temperatures sent prices sharply down and volatility reached almost 30\%. The CATS pipeline outage in July 2007 reversed the price trend, sending prices upwards and contributing to an even higher volatility. ${ }^{40}$

3. $12 / 2007-5 / 2011$-- Arbitrage with the continent led to increases in prices while volatility fell.

This period is best explained using a graphic from the Rogers 2010 paper shown in Figure 21. The figure shows that, starting in January 2008, UK NBP spot prices began to converge with continental oil-indexed prices. This continued through autumn 2008, which is also the period characterized by significantly lower volatility levels than in the previous years. During this time the UK gas market tightened, yet because of increased demand in Asia less LNG was available for the UK. Arbitrage between UK spot gas and oil-indexed contract gas on the European continent, facilitated by the Interconnector pipeline, appears to have caused price convergence and low volatility.

In January 2009, because of a Russia-Ukraine crisis, all Russian gas transiting via Ukraine to Europe was cut off for two weeks. ${ }^{41}$ Interestingly, the natural gas markets reacted with only a

\footnotetext{
${ }^{38}$ Eurogas Study on Oil-Gas Price Linkage in the European Union, Eurogas, November 26, 2001, http://www.eurogas.org/uploaded/01N0094\%200ilGas\%20Price\%20linkage\%20in\%20the\%20European\%20Union.pdf

${ }^{39}$ Stern 2006, pp 8,9

40 'CATS pipeline set to return in Mid September, Powerisk, August 31, 2007

http://www.powerisk.com/news/2007/august/cats_pipeline_set_to_return_in_mid_september.htm

${ }^{41}$ Pirani et al, 2009
} 
very brief price increase and a corresponding volatility spike of $22 \%$, the price subsequently continuing to trend downwards. This followed the onset of the global financial crisis in late 2008, when demand collapsed while supply became abundant because of global LNG supply growth.

\section{Figure 21: UK NPB and German BAFA prices}

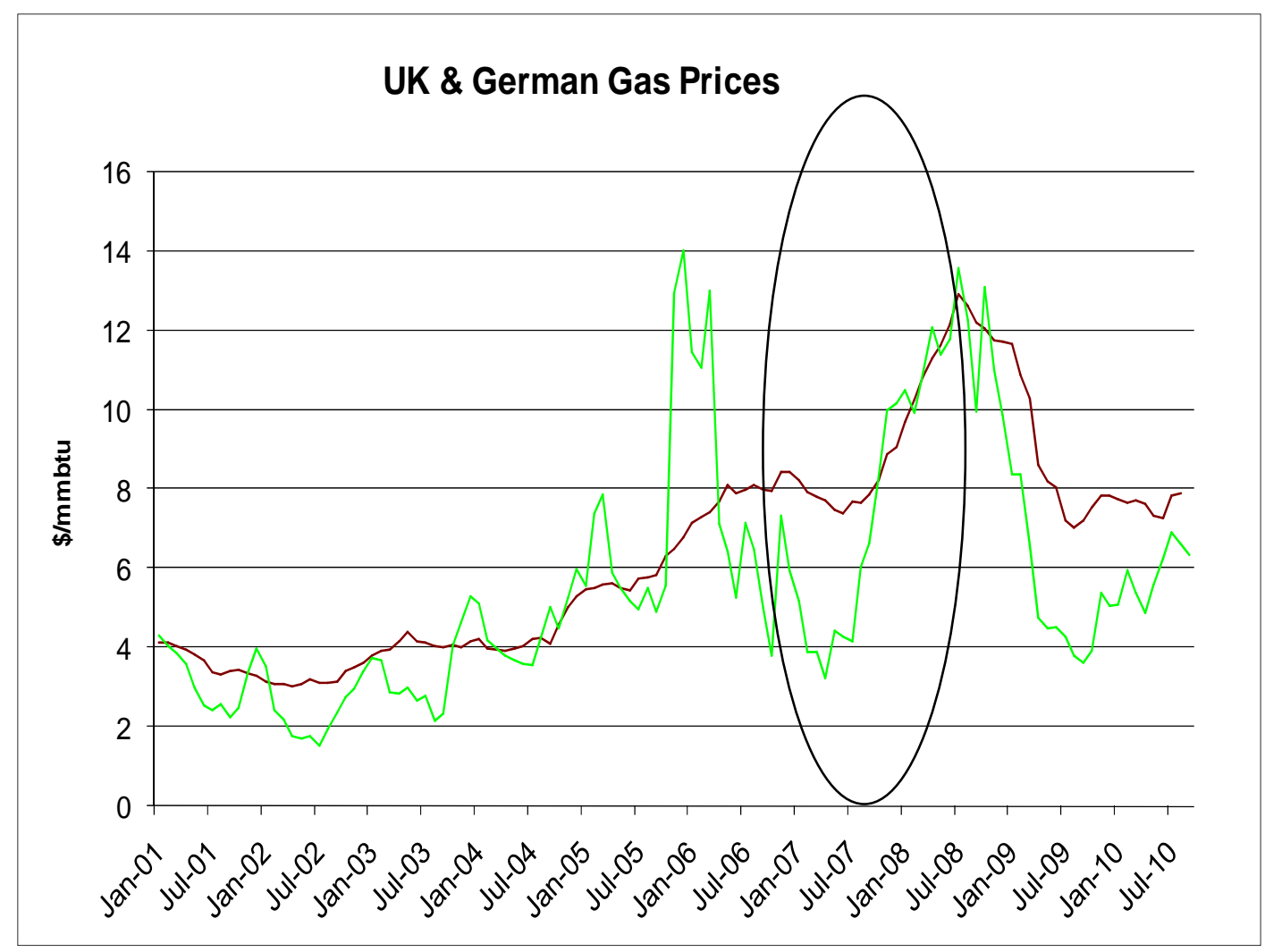

Source: Platts, BAFA

Overall, the analysis shows that price volatility levels in the UK gas market are closely linked to the availability of supply to meet prevailing demand. In tight supply scenarios, exogenous events that affect supply, such as unplanned maintenance and outages, political and policy events threatening the flow from the European suppliers and availability of LNG, have led to significant volatility spikes. However, during periods of plentiful supply these factors have a much less pronounced effect. One example is the reaction of the natural gas price to the Russia/Ukraine conflicts in 2006 and 2009. While the 2009 conflict was more severe than that of 2006, resulting in a two-week disruption of Russian gas flowing to Europe through Ukraine, the volatility response to the 2009 incident was significantly lower. The 2006 incident resulted in a volatility spike of $37 \%$ while the 2009 incident resulted in volatility increase to only $22 \%$. 


\section{Gasoil and heating oil volatility: factors and linkages to natural gas}

\section{Overview}

Heating oil (or gasoil in Northwest Europe) is a product of the crude oil refining process and trades actively on major US and European energy hubs. Like natural gas, heating oil is used for residential and commercial space heating. In the power generation sector, some participants have historically had significant fuel-switching capability which allowed them to switch between natural gas and oil products depending on their relative prices, thus influencing the demand for each product. While no reliable data exist with respect to the proportion of users that currently have a fuel-switching capability, identified sources indicate that it is fairly small, (below $10 \%$ of demand in the $\mathrm{US}^{42}$ ) and similarly small and declining in Europe. ${ }^{43}$

Given the discrepancy between the prices of gas and oil in the latter half of the 2000s, and the projections of abundant future natural gas supplies, end-users have chosen natural gas as the cheaper fuel and many have chosen not to build new switchable fuel capability. Moreover, even when the fuel-switching capability is in place, it is a difficult and time-consuming process to switch between the two fuels. Thus, the gas market is unlikely to respond to a significant change in the prices of heating oil/gasoil in the short term, and in the long run it is unlikely that consumers building new fuel-burning equipment will choose to opt for oil products instead of gas, due to the cost of maintaining oil burning equipment and substantial stocks of oil products and tightening environmental standards in relation to emissions. ${ }^{44}$

\section{Heating oil and gasoil analysis}

Analyzing the heating oil (US) and gasoil (Northwest Europe) price volatility over a period from 2000 to 2011 produced several relevant conclusions.

Figure 22 shows a comparison between the price volatility of heating oil and gasoil. Our hypothesis was that given the different quality of crude in the US and Northwest European as well as consumption differences between the two markets, the volatilities of these products may not have a high correlation. However, as the above graph shows, there is a significant correlation in the price volatility of these commodities, calculated as $69 \%$ over the observed period, signifying that the price volatility of heating oil and that of gasoil rise and fall in tandem.

\footnotetext{
42 'Oil to natural gas price ratio to stay at 6:1', Commodity Online, July 10, 2009, http://www.commodityonline.com/news/Oil-to-natural-gas-price-ratio-to-stay-at-61-19456-2-1.html

${ }^{43}$ Stern 2007, P 14

${ }^{44}$ Stern and Rogers 2011, P 3
} 
Figure 22: Volatility of heating oil and gasoil

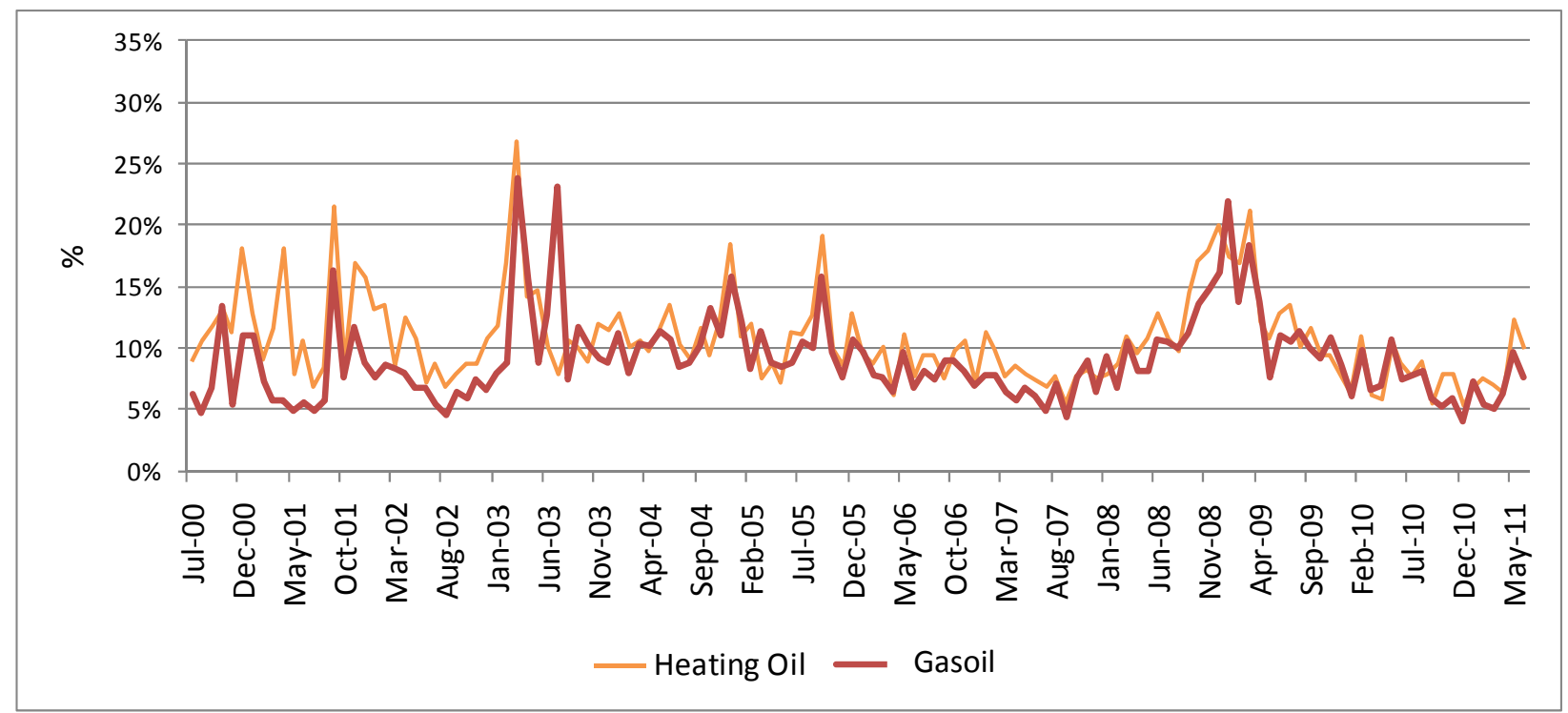

Source: Author's own analysis

Figures 23 and 24 compare the price volatility of heating oil and gasoil with the price volatility of crude in their respective markets.

Figure 23: Volatility of heating oil (US) and WTI: 2000 - 2011

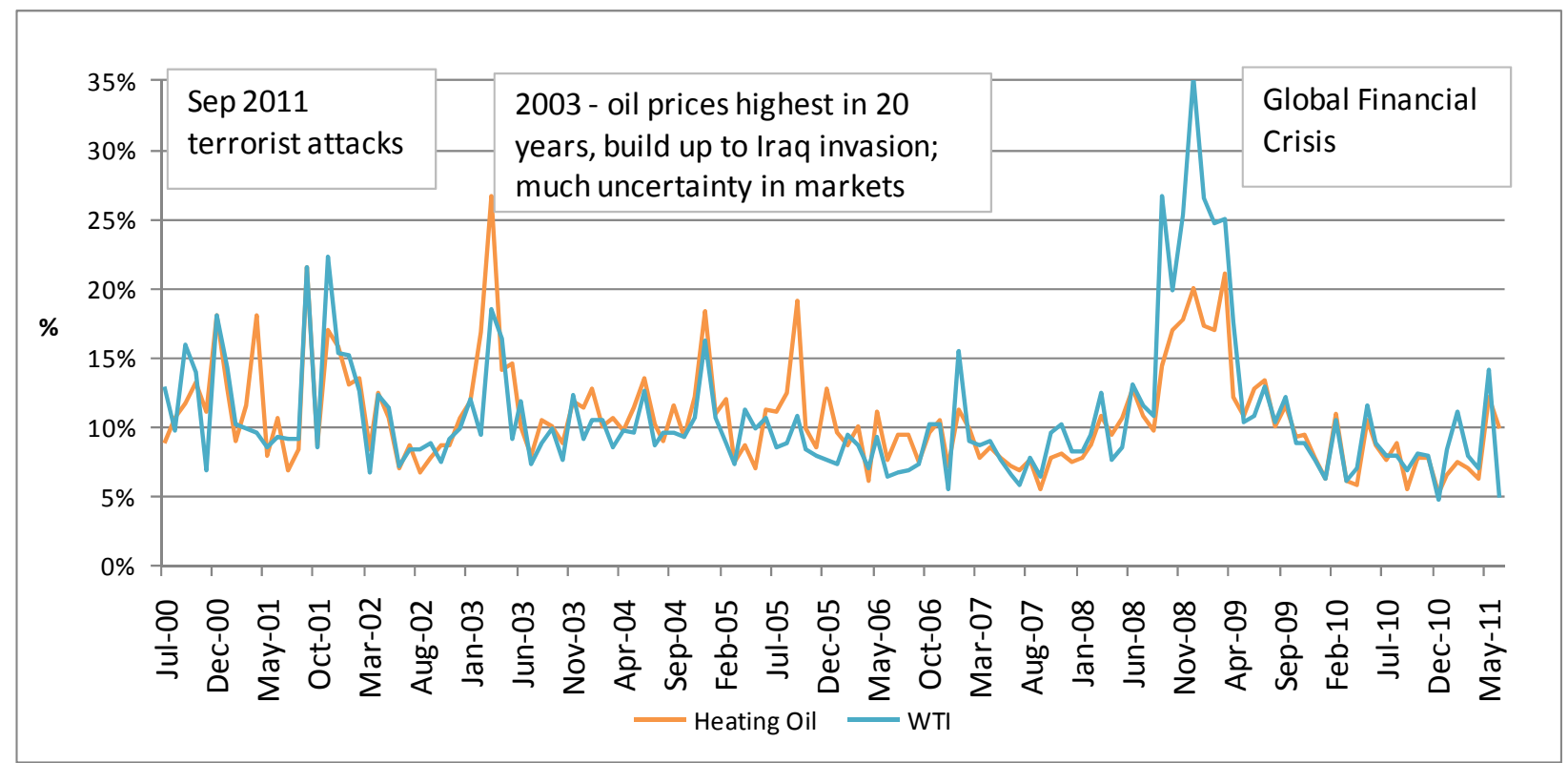

Source: Author's own analysis 
Figure 24: Volatility of gasoil (NWE) and Brent

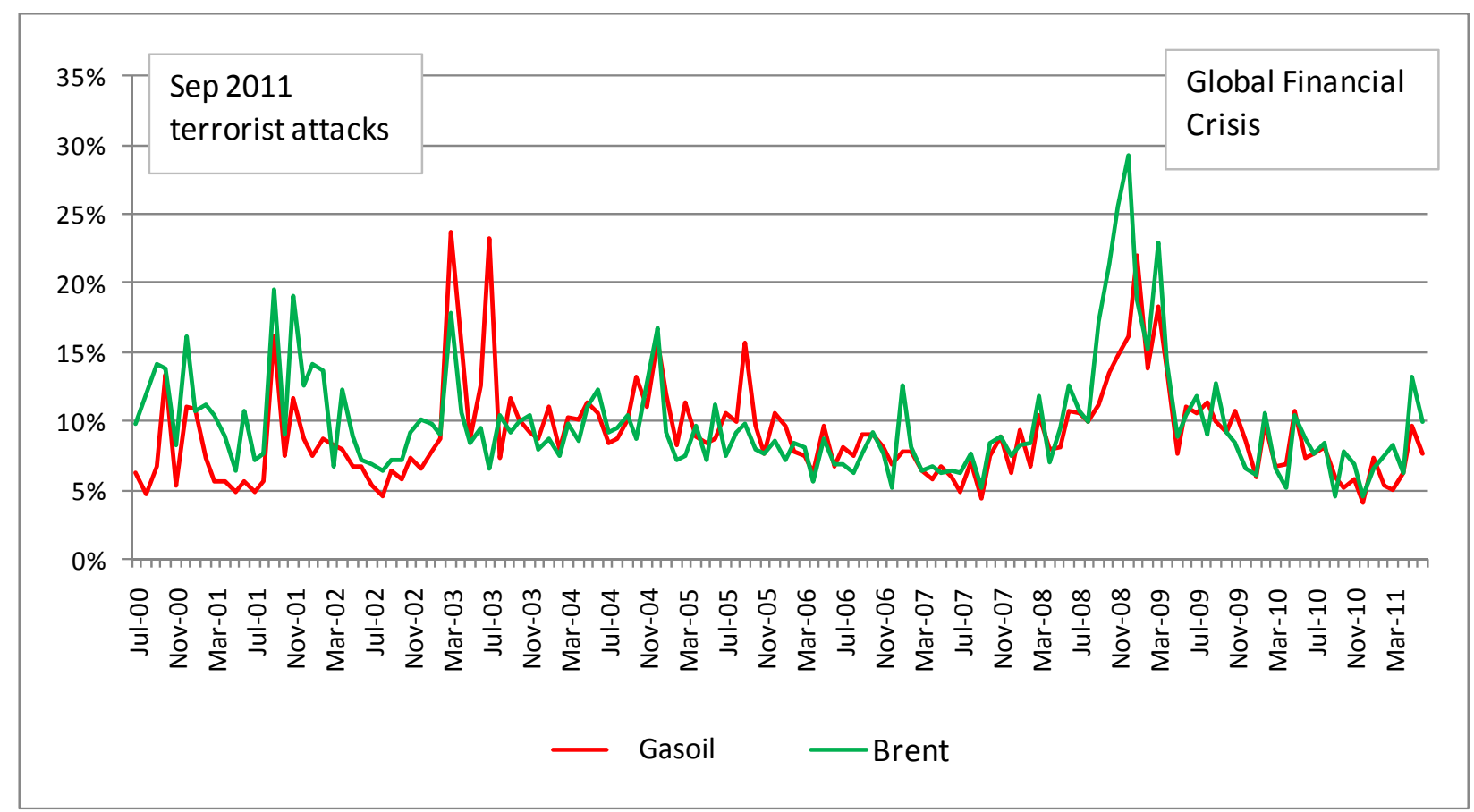

Source: Author's own analysis

As expected, the graphs above show a high level of correlation between heating oil or gasoil and their respective crude oil regional prices. The correlation between heating oil and WTI is $76 \%$ while the correlation between gasoil and Brent is $63 \%$. The difference between the two correlations is likely to be due to the difference between the stocks and storage capacity for oil products available in each region.

Other important conclusions are:

-- Heating oil and gasoil volatility, while following that of their respective crudes, tends to rise less with an increase in the volatility of the underlying crude. This can be shown by calculating the standard deviation of volatilities for each. For example, the standard deviation for WTI volatility is $4.5 \%$, while the standard deviation for volatility for heating oil is only $3.7 \%$.

Similarly, the standard deviation of volatility for Brent is $3.8 \%$, while the standard deviation of volatility for gas oil is $3.5 \%$.

-- The volatility of crude products rises above the volatility of the crude in several instances during the observed period, which might be attributed to market concerns over the ability of refiners, possibly operating at capacity, to process the amount of crude required by the market. 


\section{Linkages to natural gas}

Given the historical link between the prices of natural gas and oil products described earlier, it is important to compare volatilities for these commodities. Contrary to our expectations, we found that the correlation of the two commodities in their respective markets varied significantly: the correlation between heating oil and Henry Hub volatilities equalled to 31\% (Figure 25), and the correlation between gasoil and NBP was very low, in fact negative. This phenomenon is explained in detail below.

\section{Heating oil}

Figure 25: Price volatility of heating oil and Henry Hub front month

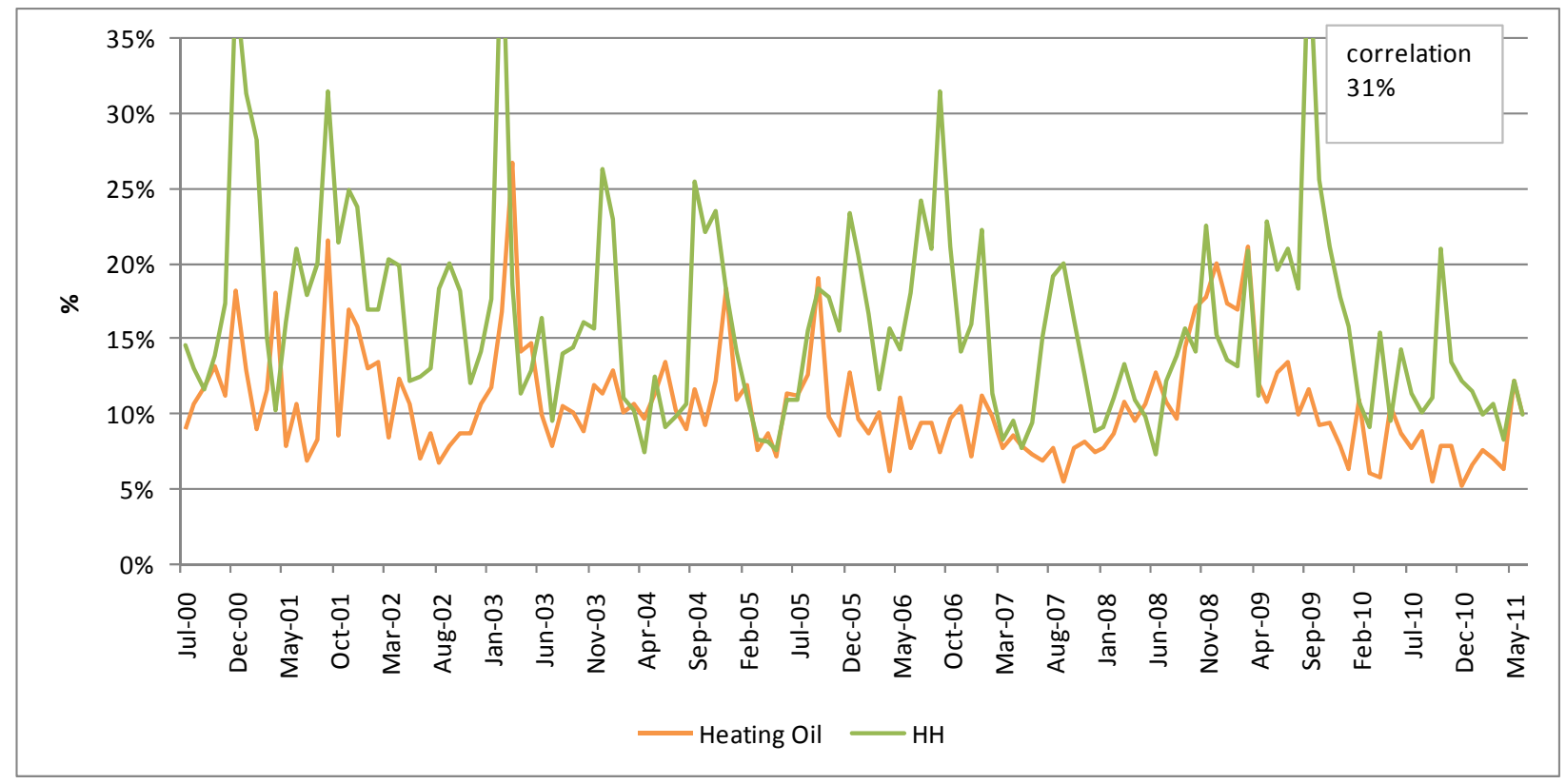

Source: Author's own analysis

In order to understand the high level of correlation between oil products and natural gas in the US market, the observation period was divided into two sub-periods (2000-2005 and 2006-2011) to identify whether the observed correlation of $31 \%$ was consistent throughout the period. The calculations showed that the correlation between heating oil and natural gas front-month contract volatilities in these two periods differs considerably. See Table 2.

Table 2: Volatility correlations: heating oil against Henry Hub and WTI

\begin{tabular}{|l|r|r|r|}
\hline Correlations Table & $2000-2011$ & $2000-2005$ & $2006-2011$ \\
\hline Heating Oil Volatility vs Henry Hub Front Month Volatility & $31.4 \%$ & $38.4 \%$ & $17.5 \%$ \\
\hline Heating Oil Volatility vs WTI Volatility & $76.2 \%$ & $70.6 \%$ & $90.0 \%$ \\
\hline
\end{tabular}

Source: Author's own analysis 
Given that throughout the period the correlation between heating oil and WTI volatilities stayed relatively high, this difference in volatility of heating oil and the Henry Hub front month contract between the two periods can only be explained by a difference in the natural gas market fundamentals. And indeed, as highlighted earlier in this paper, 2006 marked the beginning of the 'shale era' in the US, creating an abundant natural gas supply in this market. Under these conditions, the natural gas price began to decouple from the oil price as intermittent physical burner tip competition in the power sector declined. In addition, during this period, fuelswitching capability continued to decrease, further weakening the link between natural gas and heating oil.

\section{Gasoil}

Figure 26 depicts the price volatility of NBP and price volatility of gasoil during the period from 2000 to 2011 . The figure shows a correlation of $-1.6 \%$ between these two data sets.

Figure 26: Price volatility of gas oil and NBP front month (controlled)

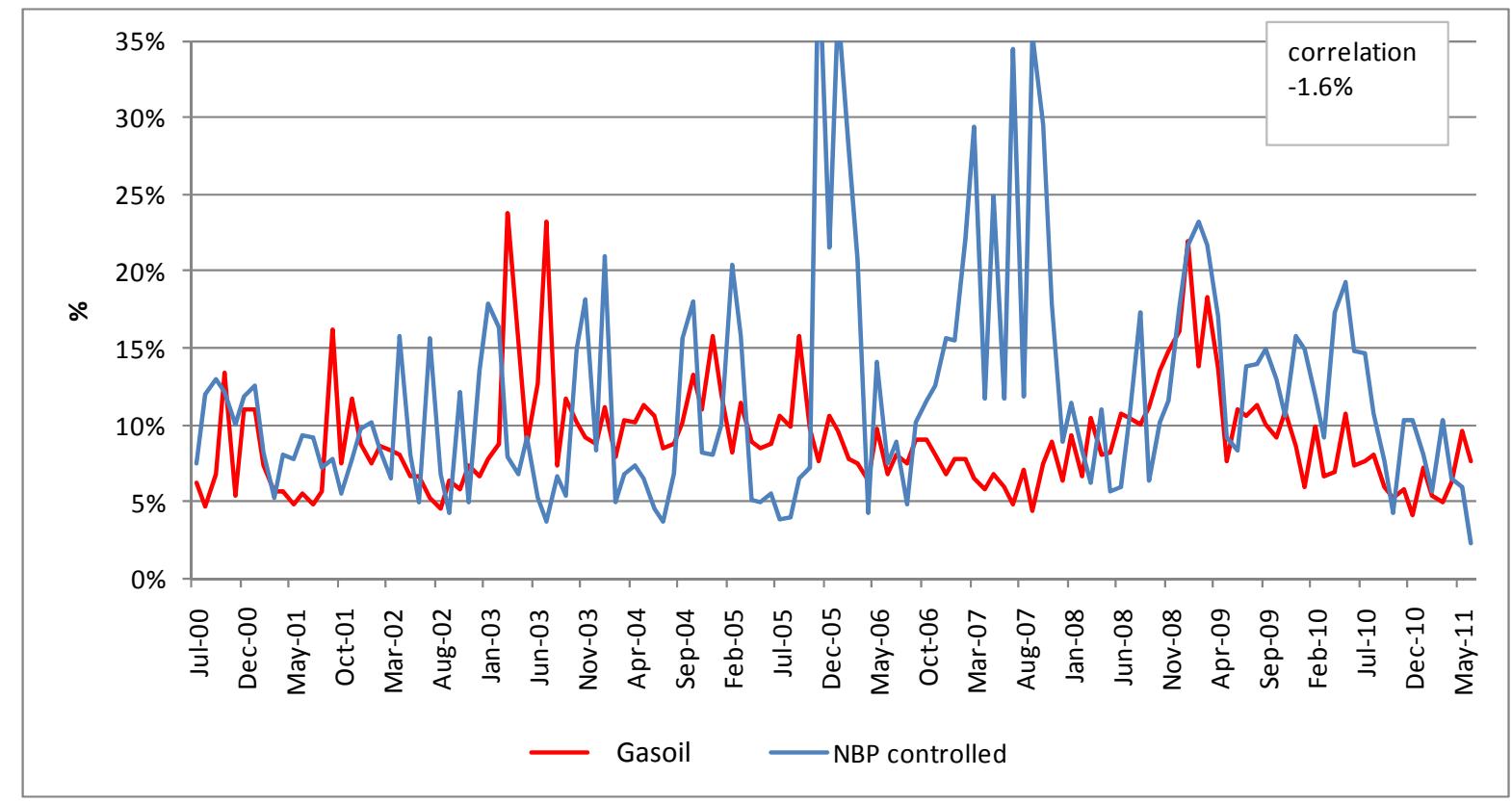

Source: Author's own analysis

In order to understand the lack of correlation between the volatilities of the gasoil front-month contract and the natural gas front-month contract in North West Europe, we once again divided the observed period into several sub-periods. Table 3 illustrates the findings. 
Table 3: Volatility correlations: gasoil against NBP and Brent

\begin{tabular}{|l|r|r|r|r|}
\hline Correlations Table & \multicolumn{1}{|c|}{$2000-2011$} & $2000-2005$ & $2006-2011$ & $2008-2011$ \\
\hline Gas Oil Volatility vs NBP Volatility (controlled) & $-1.60 \%$ & $-8.93 \%$ & $10.30 \%$ & $56.80 \%$ \\
\hline Gas Oil Volatility vs Brent Volatility & $62.90 \%$ & $40.80 \%$ & $83.80 \%$ & $83.86 \%$ \\
\hline
\end{tabular}

Source: Author's own analysis

From 2006, natural gas volatility became positively correlated with gasoil volatility. However, as discussed earlier, arbitrage between NBP and Continental European oil-indexed contract prices is unlikely to explain this, given that the latter is based on a 6-to-9 month average of gasoil and fuel oil prices. It is possible that the 2008 run-up in commodity prices in general, followed by the subsequent fall in commodity prices in 2009 , is responsible for the correlation shown here.

Another important consideration in analyzing gasoil is its role in the transportation sector in Europe. The demand for gasoil in the transportation sector in Spain, Italy and France is 2 to 4 times greater than the combined demand in all stationary sectors, such as power generation, space heating and industrial. Thus the demand dynamics in the transportation sector, specifically the lack of substitutes and therefore a more constant demand pattern, could arguably be more important in determining price than demand in the stationary sectors where switching could occur. ${ }^{45}$

${ }^{45}$ Stern 2007, P 15 


\section{Conclusions}

The analysis in this paper leads to the clear conclusion that natural gas price volatility substantially exceeds that of crude oil. On average, the volatility of Henry Hub and NBP futures exceeds the volatility of WTI and Brent futures by a factor of 1.5. The reasons for the difference fall into two broad categories: one, structural - related to the storage, transportability and market structure of each commodity - and, two, consumption patterns.

\section{Structural factors}

1. Transportability and storage. Natural gas, due to its physical characteristics and much lower energy density, cannot be transported as easily as oil and requires a dedicated network of pipelines for transportation and delivery to end-consumers. Similarly, natural gas storage is also more difficult and expensive to construct and operate than oil storage tanks for a comparable energy quantity. Natural gas is typically stored in depleted reservoirs or salt caverns, which require a base volume or 'cushion' of gas before the necessary pressure can be achieved to be able to inject and withdraw gas for consumption. While storage generally acts as a buffer against volatility, it is costly to provide. However, if it becomes non-operational during periods of high gas demand, this can lead, and has led, to high-volatility episodes. As of May 2010, the UK market had $4.3 \mathrm{Bcm}$ of storage capacity, representing approximately $4 \%$ of its annual consumption, compared with $18 \%$ of annual consumption in the US. ${ }^{46}$ Thus, we can expect substantially higher volatility in the UK given this structural factor and a resulting dependence on imports if there is an expectation that such imports may be insufficient to adequately meet demand.

2. Market structure: regional compared with global. Unlike the oil market, the natural gas market is regional and thus responds to a different set of supply/demand market fundamentals in each of its geographic segments. Moreover, the price formation structure also differs significantly between markets. As shown earlier, while the US and UK are fully liberalized, the European market remains largely linked to oil products under long-term contracts. Asian LNG contracts are also long-term but indexed to a basket of crudes imported to Japan, also known as the 'Japanese Crude Cocktail', which creates yet another pricing structure. ${ }^{47}$ However, several linkages exist between these seemingly stand-alone markets that influence the price volatility in each. The US market, which has been the most isolated and self-sufficient gas market, became linked to the global LNG market as its imports of LNG increased between 2006 and 2008. It is likely that it will become linked to the global natural gas markets again with the approval of LNG export terminals in the US and the possibility of US exports growing in the future. The UK spot market is periodically linked to the European, largely oil-indexed contract dominated

\footnotetext{
${ }^{46}$ EIA data, Author's calculations.

47 'Asia oil-linked LNG term prices may nearly double by 2020: Barclays', Platts, April 13, 2011, http://www.platts.com/RSSFeedDetailedNews/RSSFeed/NaturalGas/8787660
} 
market by the imports/exports through the UK Interconnector pipeline (arbitrage) as well as to the flexible global LNG market.

\section{Consumption patterns}

Several consumption-related factors contribute to the difference in the levels of natural gas and crude oil volatility:

1. Natural gas exhibits a considerably higher seasonality pattern than oil and oil products. This is largely due to the differences in consumption for the two commodities. US natural gas consumption is illustrated in Figure 27 . A total of $70 \%$ of natural gas in the US is consumed by residential/commercial heating and power generation and exhibits a high degree of seasonal cyclicality. The remaining $30 \%$ is consumed by the industry and shows less seasonality.

2. In the case of oil, approximately $70 \%$ of oil (in the form of oil products) is used in the transportation industry, which tends to have considerably less seasonal fluctuation. Moreover, the transportation sector demand tends to be fairly inelastic as the industry has no short-term substitute $^{48 .}$ Energy efficiency and consumption austerity measures can be taken in the long run but will have little effect in the short run.

Figure 27: US natural gas consumption by month (average 2000 - 2010)

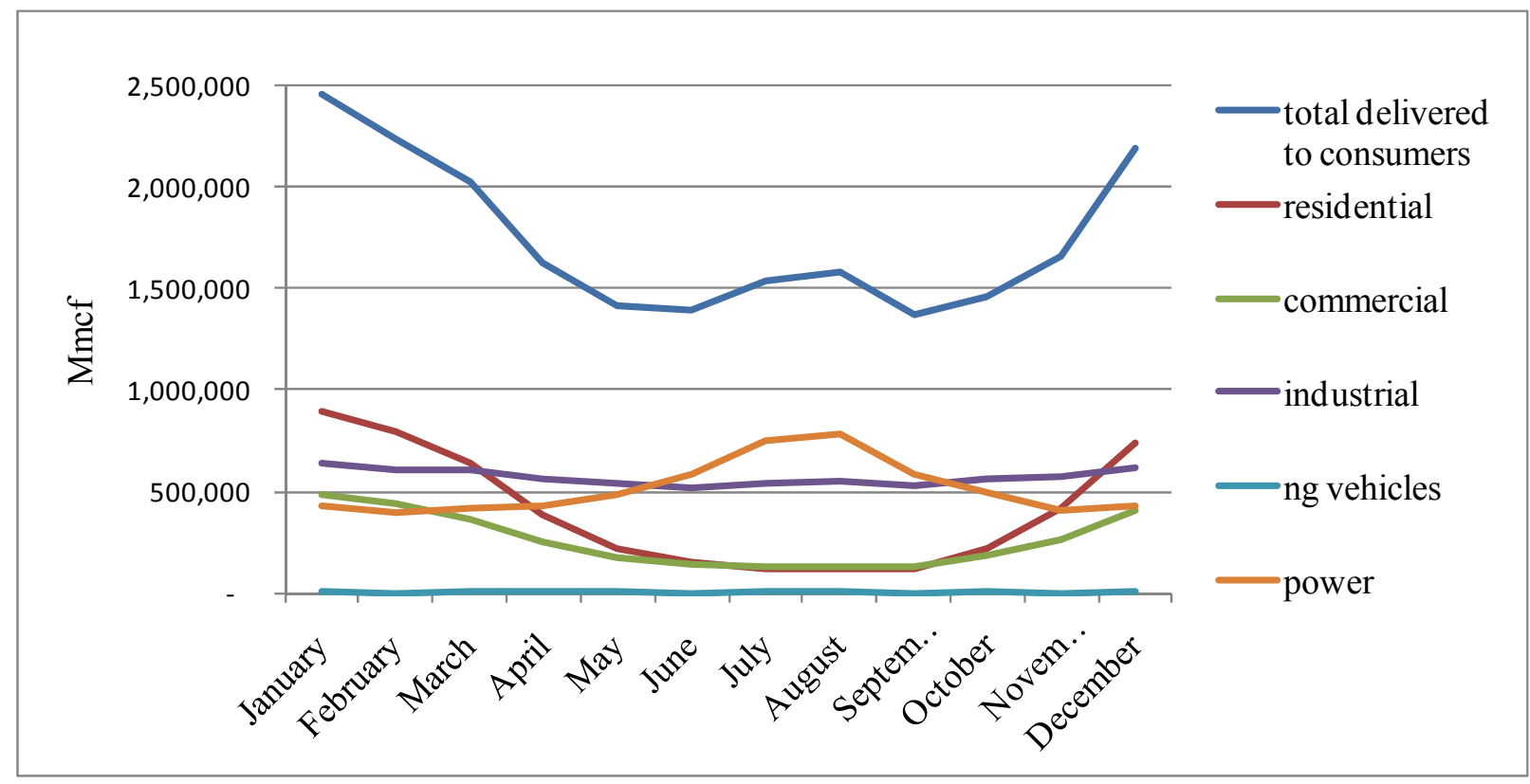

Sources: EIA, Author's own analysis

\footnotetext{
${ }^{48}$ Kahn Ribeiro, S., S. Kobayashi, M. Beuthe, J. Gasca, D. Greene, D. S. Lee, Y. Muromachi, P. J. Newton, S. Plotkin, D. Sperling, R. Wit, P. J. Zhou, 2007: Transport and its infrastructure. In Climate Change 2007: Mitigation. Contribution of Working Group III to the Fourth Assessment Report of the Intergovernmental Panel on Climate Change B. Metz, O.R. Davidson, P.R. Bosch, R. Dave, L.A. Meyer (eds), Cambridge University Press, Cambridge, United Kingdom and New York, NY, USA. http://www.ipcc.ch/pdf/assessment-report/ar4/wg3/ar4-wg3-chapter5.pdf
} 


\section{Henry Hub and the NBP}

Our analysis of the two liberalized natural gas markets produced the following conclusions.

1. Both markets, though characterized by different production, storage, import capacity and weather conditions, showed a similar response to the overarching supply and demand fundamentals. Specifically, both markets reacted strongly to demand shocks in an environment where supply sufficiency was uncertain. However, in the periods when supply was plentiful (before 2005 and after 2009 in the UK, and after 2006 in the US) the market showed a much lower volatility response to both supply events, such as the 2009 Russia/Ukraine crisis, and demand events. Examples of the latter were the colder than average winters of 2008 and 2009 in the US and the severe winter of 2010/2011 in the UK, which was the coldest in Britain for 31 years yet produced volatility below $10 \%{ }^{49}$

2. In both markets, storage and import capacity played a significant role, influencing supply during the observed period. In the US, storage remains the main instrument of flexible seasonal supply. With the onset of shale gas production, US levels of natural gas in storage have been rising consistently, contributing to a low volatility environment. In the UK, the lack of storage has become an important issue as the country now relies on imports for flexible supply - a situation posing potential security of supply concerns, especially if key infrastructure becomes inoperable due to technical problems.

3. In both markets weather is the main driver of demand, given the consumption patterns described above.

4. In the UK in 2008, arbitrage between spot gas and oil-indexed contract gas on the European continent appeared to result in a period of low volatility.

\section{Gasoil and heating oil}

As part of the study gasoil and heating oil volatilities were analyzed with a goal to understand whether, due to the historical link between natural gas and crude oil products, the volatility of these products would mimic that of natural gas. Our findings show, however, that the price volatility of oil products not only showed an absolute level very close to that of crude oil but also showed a high correlation with crude oil. When comparing the correlations between the oil products and the gas markets, we found that in the US heating oil and Henry Hub futures volatility showed a $31 \%$ correlation, while in the UK the correlation between NBP and gasoil volatility was negligible. This may be due to a historically higher proportion of switching capacity in the US than in the UK power sectors.

\footnotetext{
${ }^{49}$ Winter of 2010-2011 in Great Britain and Ireland

http://en.wikipedia.org/wiki/Winter_of_2010\%E2\%80\%932011_in_Great_Britain_and_Ireland
} 


\section{Future trends}

While the above analysis has identified the main drivers for periods of above or below average volatility in the 1997 to 2011 period, predicting future volatility trends is subject to significant uncertainty. If, as is the case in late 2011, abundant levels of supply persist in the US because of shale gas production, and in the UK as a result of plentiful LNG supply and depressed global demand, Henry Hub and NBP price volatility should remain at the low levels seen since 2009. In the US the winter of 2011/2012 should bring no exceptional volatility. However, US gas price volatility levels may change if future LNG exports result in a tighter US domestic supply situation. Currently, there are nine US and Canadian possible LNG export projects, with a total capacity of $128 \mathrm{Bcma}$ or $44 \%$ of the total global LNG supply in $2010 .^{50}$ The scale of export capacity becoming operational from 2015 onwards and the trajectory of future shale production growth is likely to combine to become the driving force for future natural gas price volatility in the US. Should the growth of shale production falter or stagnate and the US become a significant LNG importer, price volatility is likely to increase dramatically, with the tightening of domestic supply and linkage to the global LNG market.

In the case of the UK, global LNG dynamics will be one of the main factors influencing NBP volatility. By the end of 2011, the diversion of LNG supply away from the UK and Europe was already underway. The impact of the Fukushima incident in increasing Japan's LNG consumption coupled with continuing strong LNG demand growth from elsewhere in Asia, in the context of modest growth in global LNG supply prior to 2015, points to a tightening LNG market between 2012 and 2014. With a stronger LNG pull towards Asia in this period, the NBP price may well rise until it converges, through arbitrage, with European oil-indexed prices. ${ }^{51}$ While a tighter market would be expected to result in increased NBP volatility, the apparent reduction in volatility as a result of NBP and oil-indexed convergence through arbitrage, which occurred in 2008, could override this.

Beyond 2015, this equilibrium could be disturbed by the next wave of LNG projects currently under construction, notably in Australia. North American LNG exports would add to this additional supply surge. ${ }^{52}$ The uncertain future demand trajectory of Asia is also a key consideration in how the regions of Europe, North America and Asia, connected by LNG tradeflows, will attain a stable supply-demand balance and, in their doing so, what attendant levels of natural gas price volatility will pertain during the transition.

\footnotetext{
${ }^{50}$ Rogers 2012

${ }^{51}$ Rogers 2012

${ }^{52}$ Howard Rogers in his 2012 paper explores the interaction of LNG and pipeline gas pricing under several supply and demand scenarios.
} 


\section{Appendix A}

\section{Data selection}

It was recognized that in order to undertake comparative analysis of the price data sets, it was necessary to ensure that the data sets for oil and gas 'matched' in terms of trading timeframe. Natural gas generally trades in terms of a spot or cash market (for immediate delivery) or for delivery in the future: day-ahead, month-ahead and many intermediate periods as well as in a series of longer-dated futures. Crude oil, however, is generally traded on a front-month basis as well as in a series of longer-dated futures. Choosing front-month futures for the purpose of comparing the price volatility of both commodities assures the avoidance of timeframe inconsistencies while selecting data which still represents the spot (or prompt) markets. This is desirable since prompt prices are more likely to reflect the impact of ongoing changes to market fundamentals when compared with long-dated futures.

Data on spot market prices for natural gas (which are based on over-the-counter trades) are collected by several market reporting sources, including ICIS Heren, Platts and Argus. However, for the purposes of this analysis, the spot price data does not reflect the large number of transactions which is the case with the price of contracts traded on an electronic exchange such as ICE or NYMEX. ICIS Heren, for example, assesses the over-the-counter gas market prices on a daily basis by contacting by phone a wide range of active market participants ${ }^{53}$ while the ICE exchange closing price is assessed electronically using the weighted average of all trades during a fifteen-minute settlement period from 16:00 London time ${ }^{54}$. For this reason, the exchange traded data set was selected for this analysis.

While the data set of front-month natural gas and crude oil prices based on OTC contracts was not selected as the main data source for this paper, it was reviewed and compared with the exchange data sets for consistency purposes. ${ }^{55}$ Several discrepancies were observed that are, however, based largely on exchange trading conventions rather than on the OTC market conventions. While several discrepancies between daily closing prices were identified, on average, over the total observed period, the aggregate discrepancy was not meaningful.

\footnotetext{
${ }^{53}$ European Spot Gas Market Methodology. http://www.icis.com/energy/gas/europe/spot-market-methodology/

${ }^{54}$ ICE Product Guide UK Natural Gas Futures.

https://www.theice.com/productguide/ProductDetails.shtml?specld=910

${ }^{55}$ We are grateful to Platts for providing us with the OTC front-month natural gas and oil price data series.
} 


\section{Appendix B}

Several methods exist for calculating price volatility. Four of these methods are described below $^{56}$.

\section{Daily price range}

The range represents the spread in prices during a specific period. In markets with a uniform product and an open bidding process (for example, the stock market), the range is often defined as the average spread between the bid price and the ask price during a specific time period. For markets where bid and ask prices are not typically available (such as natural gas markets for all locations, with the possible exception of the NYMEX Henry Hub contract) or for markets without a uniform product, the range is typically measured as the difference between the daily high price and the daily low price. When all else is equal, and where the product is uniform, an increase in the range typically indicates an increase in volatility, and/or a decrease in liquidity. A daily price range is used in the Parkinson measure of volatility, discussed below.

\section{Standard deviation}

The standard deviation in average prices represents an absolute measure of the actual price movement over a specific period. This is probably the most common method used for measuring volatility. The standard deviation represents the expected deviation from the average market price during a given period. A higher standard deviation represents greater price movement and, when looked at in absolute terms, a higher standard deviation represents greater price volatility.

\section{Coefficient of variation}

The coefficient of variation is a relative measure of price movement, and is calculated as the standard deviation divided by the mean value. The coefficient is a useful comparative measure of price volatility for different commodities when prices are measured in different units, and with different baseline prices (for example, the volatility of the electricity price compared with the that of the natural gas price).

\section{Parkinson's measure of volatility}

The Parkinson measure of volatility uses range rather than midpoint or market close data to estimate price volatility, and hence provides a measure of volatility based on the difference between high and low prices within a given time period (such as a day, or over the bidweek). It is particularly useful for exchange-traded energy products where, at any given moment, all trades

\footnotetext{
${ }^{56}$ Henning, Sloan and De Leon, American Gas Foundation 2003, P 1-11 - 1-14
} 
are made at a single price. It is less useful for comparing volatility among different products where prices may not be the same because they reflect different credit risk premiums or product differentiation. Changes in the Parkinson measure over time can be used as an indicator of changes in volatility between time periods. The volatility is estimated using the following equation:

$\operatorname{Var}(\mathrm{P})=(\ln (\mathrm{Hi})-\ln (\mathrm{Lo})) 2 / 4 \ln 2$ Where: $\operatorname{Var}(\mathrm{P})=$ Volatility of Prices; $\mathrm{Hi}=$ Daily high price 


\section{Glossary}

API: American Petroleum Institute

Bacton-Zeebrugge Interconnector: see IUK

BAFA: the German Federal Office of Economics and Export Control website which reports natural gas production, imports, exports and storage inventory

changes: http://www.bafa.de/bafa/en/index.html

Brent: Brent Crude is the biggest of the many major classifications of crude oil, consisting of Brent Crude, Brent Sweet Light Crude, Oseberg, Ekofisk, and Forties (BFOE). Brent Crude is sourced from the North Sea. The Brent Crude oil marker is also known as Brent Blend, London Brent and Brent petroleum. It is used to price two-thirds of the world's internationally traded crude oil supplies.

CATS: the UK offshore subsea Central Area Transmission System, a 223-mile pipeline system running from the Central North Sea to the CATS processing terminal in Teesside on the North East coast of England.

EIA: the US Energy Information Administration

Fuel oil: the heaviest commercial fuel that can be obtained from crude oil, heavier than gasoline and naphtha.

Gasoil: the refined petroleum fraction corresponding to diesel.

Gas storage: the storage of natural gas in either underground structures such as depleted oil or gas reservoirs, salt caverns or aquifers, or alternatively as LNG in storage tanks at regasification terminals or in LNG peak shaving facilities.

GDP: gross domestic product

Henry Hub: Henry Hub is the pricing point for natural gas futures contracts traded on the New York Mercantile Exchange (NYMEX). It is a point on the natural gas pipeline system in Erath, Louisiana, where it interconnects with nine interstate and four intrastate pipelines. Spot and future prices set at Henry Hub are denominated in $\$ / \mathrm{mmBtu}$ (millions of British thermal units) and are generally seen to be the primary price set for the North American natural gas market.

Hub : the location, physical or virtual, where a traded market for gas is established.

IEA: International Energy Agency 
ICE: the IntercontinentalExchange operates leading regulated exchanges, trading platforms and clearing houses serving global markets for agricultural, credit, currency, emissions, energy and equity index markets. ICE operates three futures exchanges, including London-based ICE Futures Europe, which hosts trading in half of the world's crude and refined oil futures contracts traded each day.

IUK: both the shorthand name for the Bacton (UK) to Zeebrugge (Belgium) Interconnector bidirectional gas pipeline and the name of the company that operates the pipeline. Import capacity 25.5 Bcma, export capacity 20 Bcma.

Langeled: the 725-mile pipeline from the Nyhamna terminal in Norway via the Sleipner riser platform in the North Sea to Easington Gas Terminal in England. Its capacity is $25.8 \mathrm{Bcma}$.

LNG: natural gas which has been cooled to minus 163 degrees Centigrade, where it exists in a liquid state at atmospheric pressure and can be transported in specially designed ocean-going tankers.

NWE: North West Europe

National Balancing Point (NBP): the UK's National Balancing Point: a virtual point (hub) in the National Transmission System where gas trades are deemed to occur. It is also used as shorthand for the UK spot gas price.

NYMEX: the New York Mercantile Exchange (NYMEX) is the world's largest physical commodity futures exchange.

Public service obligations: Directive 2003/55/EC of the European Parliament and of the Council of 26 June 2003 concerning common rules for the internal market in natural gas provides for the possibility for member states to impose public service obligations to guarantee security of supply, economic and social cohesion objectives, regularity, quality and price of the gas supply and protection of the environment.

Storage inventory: the quantity of working gas volume in US storage. Working gas is distinct from 'cushion gas', which is only withdrawn from storage when a storage site is decommissioned.

WTI: West Texas Intermediate (WTI), also known as Texas light sweet, is a grade of crude oil used as a benchmark in oil pricing. It is a light (low density) and sweet (low sulfur) crude oil. 


\section{Bibliography}

EIA 2007: An Analysis of Price Volatility in Natural Gas

Markets. ftp://ftp.eia.doe.gov/features/ngprivolatility.pdf

Farrel, Kahn, Visser: G N Farrel, B Kahn, F J Visser: Price determination in international oil markets:

developments and prospects, South African Reserve Bank Quarterly Bulletin, March

2001. http://www2.resbank.co.za/internet/Publication.nsf/LADV/A173839CD77D369342256C6E002A96 A9/\$File/article219a.pdf

Fattouh 2010: Bassam Fattouh, An Anatomy of the Oil Pricing System, OIES: September 2010.

Foss 2007: Michelle Foss, Unites States Natural Gas Prices to 2015, OIES, February

2007. http://www.oxfordenergy.org/?s=ng18

Henning, Sloan and De Leon, American Gas Foundation 2003: Bruce Henning, Michael Sloan, Maria de Leon, American Gas Foundation, Natural Gas and Energy Price Volatility, October

2003. http://www.gasfoundation.org/ResearchStudies/volatility.htm

Jensen 2004: James T. Jensen, The Development of a Global LNG Market. Is it likely? If so when? OIES 2004. http://www.oxfordenergy.org/wpcms/wp-content/uploads/2010/11/NG5-

TheDevelopmentofAGlobalLNGMarketIsItLikelylfSoWhen-JamesJensen-2004.pdf

Major oil storage owners at Cushing, Oklahoma, Reuters, February 28,

2011. http://af.reuters.com/article/energyOilNews/idAFN2827076420110228?sp=true

Mu 2004: Xiaoyi Mu, Weather, Storage, and Natural Gas Price Dynamics: Fundamentals and Volatility, Department of Economics, University of Oklahoma, working paper, December 2004.

Pindyck 2004: Robert S. Pyndick, Volatility in Natural Gas and Oil Markets, The Journal of Energy and Development, Vol. 30, No. 1. Copyright 2004 by International Research Center for Energy and Economic Development.

Rogers 2010: Howard Rogers, LNG Trade Flows in the Atlantic Basin: Trends and Discontinuities. OIES, Mach 2010. http://www.oxfordenergy.org/wpcms/wp-content/uploads/2010/11/NG41-

LNGTradeFlowsInTheAtlanticBasinTrendsandDiscontinuities-HowardRogers-2010.pdf

Rogers 2011: Howard Rogers, The Impact of Import Dependency and Wind Generation on UK Gas Demand and Security of Supply to 2025, OIES: August 2011, http://www.oxfordenergy.org/wpcms/wpcontent/uploads/2011/08/NG-54.pdf

Rogers 2012,: Howard Rogers, 'The Impact of a Globalising Market on Future European Gas Supply and Pricing: the Importance of Asian Demand and North American Supply', Howard Rogers, OIES, January 2012, http://www.oxfordenergy.org/wpcms/wp-content/uploads/2012/01/NG 59.pdf 
Schmidbauer, Rosch 2011: Harald Schmidbauer and Angi Rosch, OPEC News Announcements: Effects on Oil Price Expectation and Volatility, Preprint submitted to Energy Economics, September 6, 2011, p. 15. http://www.vwl.unibe.ch/research/seminar/pdf/prof_harald_schmidbauer_2011-09-13.pdf

Stern 2006: Jonathan Stern, The Russian-Ukrainian Gas Crisis of January 2006, OIES:

2006. http://www.oxfordenergy.org/2006/01/the-russian-ukrainian-gas-crisis-of-january-2006/

Stern 2007: Jonathan Stern, Is There a Rationale for Continuing Link to Oil Product Prices in Continental European Long-term Gas Contracts? OIES, April 2007. http://www.oxfordenergy.org/wpcms/wpcontent/uploads/2010/11/NG19-

IsThereARationaleFortheContinuingLinkToOilProductPricesinContinentalEuropeanLongTermGasContract s-JonathanStern-2007.pdf

Vertical Integration and the Cushing Crunch, Commodities Now, August 1, 2011. http://www.commodities-now.com/commodities-now-news/power-and-energy/7253-verticalintegration-and-the-cushing-crunch.html 